UNIVERSITÀ CATTOLICA DEL SACRO CUORE

Dipartimento di Economia e Finanza

\author{
Working Paper Series
}

Supply Chain Control: a Theory

of Vertical Integration

Giovanni Ursino

Working Paper n. 27

June 2015

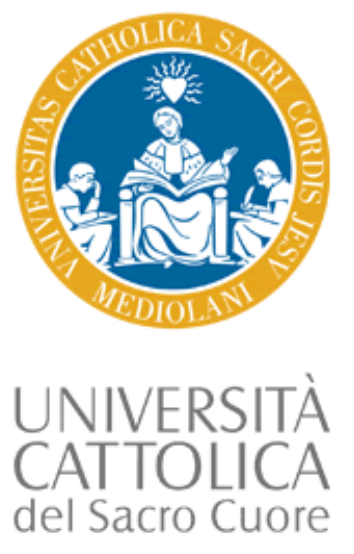




\title{
Supply Chain Control: a Theory of Vertical Integration
}

\author{
Giovanni Ursino \\ Università Cattolica del Sacro Cuore
}

Working Paper n. 27 June 2015

\author{
Dipartimento di Economia e Finanza \\ Università Cattolica del Sacro Cuore \\ Largo Gemelli 1 - 20123 Milano - Italy \\ tel: +39.02.7234.2976 - fax: +39.02.7234.2781 \\ e-mail: dip.economiaefinanza@unicatt.it
}

The Working Paper Series promotes the circulation of research results produced by the members and affiliates of the Dipartimento di Economia e Finanza, with the aim of encouraging their dissemination and discussion. Results may be in a preliminary or advanced stage. The Dipartimento di Economia e Finanza is part of the Dipartimenti e Istituti di Scienze Economiche (DISCE) of the Università Cattolica del Sacro Cuore. 


\title{
Supply Chain Control: a Theory of Vertical Integration*
}

\author{
Giovanni Ursino ${ }^{\dagger}$ \\ May 7, 2015
}

\begin{abstract}
Improving a company's bargaining position is often cited as a chief motivation to vertically integrate with suppliers. This paper expands on that view in building a new theory of vertical integration. In my model firms integrate to gain bargaining power against other suppliers in the production process. The cost of integration is a loss of flexibility in choosing the most suitable suppliers for a particular final product. I show that the firms who make the most specific investments in the production process have the greatest incentive to integrate. The theory provides novel insights to the understanding of numerous stylized facts such as the effect of financial development on the vertical structure of firms, the observed pattern from FDI to outsourcing in international trade, the effect of technological obsolescence on organizations, etc.
\end{abstract}

JEL Classification Numbers: L1, L2

Keywords: vertical integration, supply chain, bargaining, outside options

${ }^{*}$ I am grateful to Markus Möbius for his advice, to Filippo Balestrieri, Milo Bianchi, Paul Niehaus and Emanuele Tarantino for discussions, and to seminar participants at Harvard, UPF, Universität Mannheim and ECARES. I gratefully acknowledge financial support from the Associazione Borsisti Marco Fanno.

${ }^{\dagger}$ Catholic University of Milan. This paper was written while the author was visiting fellow at the Department of Economics at Harvard University. Contact: giovanni.ursino@unicatt.it. 


\section{Introduction}

I consider how vertical integration affects the bargaining power of the integrating firms against non-integrated firms in the supply chain. Integration has costs because it limits an assembler's flexibility in choosing the most suitable suppliers for a particular end product. However, by gaining bargaining power the assembler can appropriate a larger share of the total revenue which can make integration a profitable strategy for the assembler.

I use two examples from the $\mathrm{PC}$ and the cell phone industry to motivate my analysis. In the PC industry, IBM and Apple Inc. followed very different strategies. IBM only controlled the hardware of the original PC and had Microsoft provide the operating system. In contrast, Apple controlled both the operating system and the hardware of the Macintosh PC from the start. Within a few short years, Microsoft became the dominant player in the PC industry and in 2005 IBM exited the PC business by selling its remaining factories. Apple, on the other hand, was able to keep its PC business highly profitable and thriving. Apple's decision did not come without costs because the company was often slow in updating its operating system. ${ }^{1}$ Ultimately, however, Apple's decision to integrate software and hardware and sacrifice flexibility proved profitable. In the cell phone industry, there has been substantial disagreement about the optimal level of vertical integration and the boundary between in-house and outside procurement has shifted a number of times during the past 15 years. In the 1990s, large handset manufacturers such as Motorola, Nokia and Ericsson outsourced a lot of the design and software development to suppliers in Taiwan, Singapore and India. These suppliers gained crucial knowledge and expertise as a result, and this allowed some of them to become fierce competitors in their own right. ${ }^{2}$ The business press has acknowledged the importance of vertical integration for bargaining with suppliers. For example, the Financial Times stated in a special report on vertical integration that "Another reason to integrate vertically is to affect bargaining power with suppliers" (November 29, 1999).

In my model, each final product requires a continuum of inputs which are each produced by a specialized supplier. Inputs in my model are complements and each supplier has ex-ante equal ability to hold up assembly of the final product. I assume

\footnotetext{
${ }^{1}$ For example, Windows 95 was considered a more stable system than the Apple OS 7 . In fact, the main reason behind IBM's decision not to develop the operating system in-house was a desire to bring the PC to market as quickly as possible.

${ }^{2}$ For example, HTC now produces own brand smart phones as well as those of its clients. The same is true for Compal and the goal of Flextronics' CEO Michael E. Marks - as reported by Business Week (March 21, 2005) — is to make Flextronics a low-cost, soup-to-nuts developer of consumer-electronics and tech gear.
} 
that inputs differ in their specificity, defined by the extent to which the revenue produced by each supplier is subject to hold up. The assembler of the final product has the opportunity to purchase suppliers and integrate them into a single company. The integrated company obtains bargaining power that is disproportionately larger than the share of the production process that is being integrated in the single company. In return, the assembler loses the ability to choose the most suitable companies for production of the final product.

As long as the inefficiency that is caused by integration is not too severe, a well defined integrated equilibrium exists. I show that the vertically integrated company will incorporate those suppliers who are required to make the most specific investments. As integration affects the distribution of welfare between integrated and non-integrated firms, the intuition behind this result is that those suppliers are most vulnerable to hold-up and therefore benefit the most from the increase in bargaining power. In my basic model, integration always has negative welfare consequences because it decreases total available revenue, due to the flexibility loss. In an extension I allow firms to vary the level of investment. I show that, under certain conditions, integration can improve welfare because firms with specific investments will invest more after integration since their revenues are better shielded from expropriation.

My model predicts that the rise of modern financial markets (Rajan and Zingales (2001); Acemoglu, Johnson, and Mitton (2009)) leads to less vertical integration, a recent trend in developed economies. I also show that vertical integration goes hand in hand with technological intensity (Acemoglu, Aghion, Griffith, and Zilibotti (2010)). The prediction that a vertically integrated company incorporates those suppliers who make the most specific investments explains why Japanese auto makers have historically been unwilling to import US auto parts with high technological content (Spencer and Qiu (2001); Qiu and Spencer (2002)). Using a similar approach as in Antràs (2005) my model can also explain the recent shift from FDI to outsourcing in international trade (see also Vernon (1966)).

My work shares several characteristics with the Property Rights theory of the firm as developed in Grossman and Hart (1986) and Hart and Moore (1990). Just as in the Property Rights view, firms' investments can be appropriated by a partner. However, my model analyses the bargaining power of integrated (inside) firms versus non-integrated (outside) firms. My model also contributes to our understanding of the optimal boundary of the firm. This question was famously posed by Coase (1937) and became the cornerstone of Transaction Cost Economics (Williamson (1985), Williamson (2002)). Although my model resembles models found in the literature on vertical foreclosure (Salinger (1988), Hart and Tirole (1990), Kranton and Minehart (2002)) the mechanism is quite different. In the foreclosure literature different 
assemblers compete with each other in the final product market and deal with common suppliers - integration serves as a means to exclude the competing assembler from access to a crucial supplier. In contrast, an assembler in my model is a monopolist in the final product market. My model shares with Acemoglu, Antràs, and Helpman (2007) the way contractual incompleteness and specific investment are modeled. Moreover, it features complementarity in production technology, echoing works by Laussel (2008), Laussel and Long (2012), Matsushima and Mizuno (2012) and Reisinger and Tarantino (2013).

Finally, the idea that the bargaining stance of a firm can be strategically altered by its integration decisions has appeared elsewhere in the literature. In particular, de Fontenay and Gans (2005) analyze a model in which vertical integration affects the bargaining power of contracting firms by changing the market structure. In their model there is no efficiency cost of integration because the authors focus on the effects of vertical integration as they relate to the competitive environment. The bargaining is sequential and, together with the market structure following negotiations' breakdown, determines the profitability of integration. My model, instead, studies how the profitability of integration and its optimal extent depend on the flexibility loss of integrated firms as introduced by Williamson (1979) and on a taxonomy of investment specificity characterizing an industry.

The paper is organized as follows: in Section 2 I introduce and analyze the model, first a benchmark version and then an extended version. In Section 3 I apply the extended version of the model to provide a unified interpretation of several stylized facts, in connection with the relevant literature. Section 4.1 allows for multiple vertically integrated assemblers within the supply chain. Section 4.2 makes the investment decision of firms endogenous. Section 5 concludes.

\section{Theory}

This section introduces a simple model that exhibits the trade-off between the bargaining advantage that vertical integration provides and the loss in flexibility.

\subsection{Model Setup}

I model an industry that produces a somewhat complex final product (such as the automotive industry or the cell phone industry). The final product is assembled from a set of essential components which I index by $i \in[0,1]$. Components are essential in the following sense: a final product cannot be produced and/or sold without each and every component. In other words, the production function is Leontief and 
inputs are perfect complements. Each type $i$ component is produced by a type $i$ firm. Components are put together by an assembler. ${ }^{3}$

The timing of the game is described in detail later. I now illustrate the modeling assumptions on production technology and contractual incompleteness. In general, the extent a component fits the end product varies, adding more or less to its value. ${ }^{4} \mathrm{I}$ keep it simple and assume that each component can be either "perfect" or "imperfect" for the final product. I simplify further assuming that, albeit essential, imperfect components add no value to the final good, while the share of perfect components in a product, $x$, determines the value of the final product in the market. For the sake of simplicity I assume a simple linear specification and define the final revenue, $S$, as:

$$
S=\pi x
$$

where $\pi>0$ is a profitability parameter. A fixed investment is required for the production of each component. I normalize the required investment to zero and take for granted that investments are made throughout the paper. ${ }^{5}$ Therefore, total profits for a final product with a share $x$ of perfect components equal total revenue $\pi x$. Notice that, because there is a unit mass of firms, total profits and single firm profits are both equal to $S$.

Contracts are incomplete and firms differ in their ability to appropriate the revenue $S$. Sticking with the literature, by "ability to appropriate" I mean being entitled to claim by a legally binding contract based on court-verifiable evidence. ${ }^{6}$ In particular I assume that each firm type $i$ can appropriate a share $1-s(i)$ of the revenue it produces so that firm $i$ is able to claim the revenue $S[1-s(i)]$, where $s(i) \in[0,1]$. The remaining revenue, $S s(i)$, which firm $i$ cannot claim because of contract incompleteness, adds to the bargained surplus, $\tilde{S}=S \int_{0}^{1} s(i) d i$, and is subject to negotiation between firms which I describe in greater detail below. The function $s(i)$ is the specificity function and captures the extent to which a firm's claim to the revenue

\footnotetext{
${ }^{3}$ For a similar set-up see Laussel (2008) and Laussel and Long (2012). In these works, however, component producers are symmetric while here they are crucially different as to how specific is the investment needed for their production, as it will be clarified later.

${ }^{4}$ For instance, its design may be carefully thought for best fitting a specific end product or rather be of more general purpose, fitting several end products just well.

${ }^{5}$ In section 4.2 I show how incentives change when the amount of investment is a choice variable.

${ }^{6}$ Example: a firm supplies a widget whose production costs are only partially verifiable. The costs' share which is verifiable can be appropriated by the firm on a contractual basis -because, for instance, receipts can be exhibited. The costs which are harder to prove, instead, should be bargained over outside the legal bounds of the contract. In other words, contracts are incomplete: for part of the costs they give tile to precise claims by the parties, but for some costs they leave to bargaining the determination of each party's compensation.
} 
is subject to negotiation between firms. For example, the revenue of a firm with specificity $s(i)=1$ fully depends on its ability to negotiate with other component suppliers. On the other hand, a firm with specificity $s(i)=0$ does not have to bargain at all. Hence, firm $i$ produces a more specific component than firm $i^{\prime}$ if $s(i)$ is larger than $s\left(i^{\prime}\right)$ and vice versa.

I consider the specificity function as determined by the interplay between contractual incompleteness and component complexity: the more sophisticated a component is, the more it is difficult to specify a supply contract for it. ${ }^{7}$ I assume without loss of generality that $s(i)$ is decreasing — so that a higher index $i$ corresponds to a lower component's specificity. $^{8}$ In Section 3 I analyze how vertical integration decisions differ across industries with different specificity functions.

The remainder of the model describes precisely how firms divide the appropriable revenue $\tilde{S}$ among themselves and how they can affect the distribution of revenue through vertical integration. The structure of the game is common knowledge.

Stage 1: Integration Decision. In the first period the assembler offers to buy a subset $I \subseteq[0,1]$ of component firms. Those who accept the offer become divisions of a new vertically integrated firm where the assembler is the unique owner and manager. ${ }^{9}$ The set $I$ has measure $N$ with $N=\int_{I} d i$ and $0 \leq N \leq 1$, i.e. the degree of integration pursued by the assembler may range from no integration $(N=0)$ to full integration $(N=1)$.

At this time there is still uncertainty about the desired characteristics of the final good. Hence, it is not yet known whether a type $i$ firm will be able to produce a perfect component in Stage 3 of the game - when production takes place as detailed below. I shall now introduce the following assumption.

\footnotetext{
${ }^{7}$ Modeling investment specificity without reference to the existence of a second best — outside option - market is not novel. For instance Acemoglu, Antràs, and Helpman (2007) model contractual incompleteness by allowing suppliers' activities to be only partially verifiable: the degree of verifiability of a supplier's activities is a primitive in their model and determines her bargaining outcome.

Moreover, a large literature dating back at least to Macaulay (1963) attests that, when writing breach of contract provisions, businessmen don't actually believe they have a way out the contract other than the payment of damage fees. In other words, when dealing with complex transactions, managers normally don't take it seriously the existence of an outside market to sell their specific components in case the original contract is breached; rather, in such cases they relay on the payment of damage fees at best.

${ }^{8}$ It could be any function mapping $[0,1]$ into itself, but for tractability and clarity of exposition I will consider only continuous decreasing functions.

${ }^{9}$ I don't study the additional problem of how profits are shared within the firm and consider the new integrated firm as a single entity.
} 
A1 Non-integrated suppliers produce perfect components. Suppliers which are integrated in Stage 1 produce perfect components with probability $\gamma<1$.

Assumption A1 is stronger than necessary and is made so for simplicity. The model would deliver similar results if the ex-ante probability of making a perfect component ex-post was just higher for a non-integrated supplier vis-à-vis an integrated one. The rationale behind this assumption is that the management of larger organizations suffers bureaucratic burdens as well as longer command chains which make decision making relatively complex and slow as compared to small firms which are more flexible and quickly adapt to changes in the environment. ${ }^{10}$ Legros and Newman (2013), for instance, argue that integration between two firms is costly because it requires adaptation to each other technological approaches. ${ }^{11}$ Thus, the parameter $\gamma$ captures the flexibility loss caused by vertical integration: the lower $\gamma$ the higher the efficiency cost of vertical integration. ${ }^{12}$

Stage 2: Contracting. In the second stage of the game the vertically integrated firm and the non-integrated suppliers sign a long term incomplete contract for the production and assembly of the final good. However, before entering Stage 2, the uncertainty about the characteristics of the final product is resolved (e.g. volatile demand trends become clear) and it becomes known to everybody whether a supplier is capable of delivering a perfect component. Therefore, the integrated firm will enter the contracting stage being able to produce a fraction $\gamma$ of perfect components out of the $N$ it produces internally, while external suppliers enter contracting with perfect components. Thus, the final good will be assembled using a number of perfect components equal to:

$$
x=1-N+N \gamma .
$$

Clearly $x<1$ whenever $N>0$ and, from (1), the value of a final product when there is no integration and all suppliers produce perfect components $-\pi$ - is larger than

\footnotetext{
${ }^{10} \mathrm{~A}$ simple story is the following: production of perfect components in multiple-layers vertically integrated firms requires coordination across managers, which happens with, say, probability $\gamma$. Coordination is not an issue for a non-integrated supplier with a single-layer management.

${ }^{11}$ On the other hand Hortaçsu and Syverson (2007) present evidence that vertically integrated cement plants are more efficient than non-integrated ones. Interestingly, however, they find that the "productivity advantage is tied to improved logistics coordination afforded by large local concrete operations" and not "due to firms' vertical structures per se: non-vertical firms with large local concrete operations have similarly high productivity levels." Thus, their evidence is not conflicting with the traditional Transaction Cost Economics hypothesis of bureaucratic overload and is consistent with the flexibility loss assumption made here.

${ }^{12}$ In fact, $\gamma$ is a reduced form of the "bureaucratic hazards" found in Transaction Costs Economics (see Williamson (1979)).
} 
the value of the final good when the assembler vertically integrates and produces internally $N$ components $-\pi(1-N+N \gamma)$. Hence, integration induces a welfare loss because it bounds a portfolio of component suppliers together before uncertainty about a supplier's suitability for the final product is resolved. For example, a vertically integrated car manufacturer might discover that it needs to increase the share of fuel efficient cars in its line-up. However, because the company is integrated it might be forced to make use of gas-guzzling internally produced engines rather than source engines from suppliers of fuel-efficient engines because, say, it has not been able to promptly retool its engine factory. ${ }^{13}$

Stage 3: Bargaining. Investments and production take place and revenues realize. At this stage the integrated firm and the non-integrated suppliers divide the appropriable revenue $\tilde{S}(N)$ :

$$
\tilde{S}=\pi(1-N+N \gamma) \int_{0}^{1} s(i) d i
$$

I assume that firms engage in Nash bargaining. ${ }^{14}$ In case of disagreement bargaining breaks down between the integrated assembler and non-integrated suppliers at the same time. ${ }^{15}$ In this case, owing to the Leontief nature of the production function, the components produced are worthless unless the missing components are replaced. I assume that the integrated assembler can find in the market fringe suppliers to replace the missing components. As to the quality of such components I assume what follows.

\section{A2 Fringe suppliers produce imperfect components.}

\footnotetext{
${ }^{13}$ Of course, as highlighted in the vertical foreclosure literature, an integrated assembler might as well procure internally and from external suppliers at the same time, possibly at a higher cost. The results in the paper would equally hold if one assumed that double sourcing has sufficiently high costs -because of, say, unproductive sunk costs and underutilized factories.

${ }^{14}$ Another widely used concept is the Shapley Value. I use Nash Bargaining for two reasons: $i$ ) the strong non cooperative approach to NB (see Binmore, Rubinstein, and Wolinsky (1986) among others) fits better the zero-sum opportunistic nature of the game studied here; and $i i$ ) given the Leontief production function, the marginal contribution of each supplier in Shapley Value would be equal to the whole value of production and the resulting share would be trivially equal across suppliers.

${ }^{15}$ One may wonder what happens if bargaining breaks down between any two players rather than all at once. This can be investigated through dynamic models of bargaining such as Stole and Zwiebel (1996). However such dynamics are not essential to the point made in the present paper. For further discussion of multilateral bargaining with particular reference to countervailing buyer power see Iozzi and Valletti (2010).
} 
The rationale for this assumption is the following: one can think of fringe components as of refurbished components, such that they can be employed as poor substitutes for some missing parts but it would not be possible to assemble a final good out of refurbished components only. Assumption A2 is, again, stronger than necessary. Assuming that fringe components are perfect with a probability smaller than $\gamma$ would be enough to deliver the intuition offered in this analysis but it would greatly complicate the algebra.

Therefore, if bargaining in the last period breaks down the integrated firm will bargain with fringe suppliers in an auxiliary bargaining round where the appropriable revenue is now: ${ }^{16}$

$$
\tilde{S}^{\text {aux }}=\pi N \gamma \int_{0}^{1} s(i) d i
$$

In this auxiliary round the outside option of both integrated firm and fringe suppliers is zero, i.e. no third round is allowed. ${ }^{17}$

On the other hand a non-integrated supplier - whose mass is zero - may only get together with imperfect component producers. Hence, because of A2, the final product would have a unit mass of imperfect components in it, which makes it worth $\operatorname{nil}\left(\left.\pi x\right|_{x=0}=0\right)$. Therefore, working backward, the outside option of a non-integrated supplier in the first negotiation round is zero. ${ }^{18}$

Remark on Bargaining. One feature of Nash bargaining in the presence of a vertically integrated firm is that integration per se tends to reduce bargaining power because the relative size of players is not dealt with in the standard model. To see this, consider three firms with equal bargaining power and zero outside option bargaining over pie with unit size. Each firm receives $\frac{1}{3}$ of the pie. Now assume that two firms integrate and bargain as a single entity with the third firm. Now the integrated firm receives $\frac{1}{2}$ of the pie - therefore integration hurts a firm's bargaining power in a counter-intuitive way. ${ }^{19}$

\footnotetext{
${ }^{16}$ The difference between $\tilde{S}$ and $\tilde{S}^{\text {aux }}$ is that $(1-N+N \gamma)$ is replaced by $N \gamma$ because now, given the inferior quality of fringe suppliers' components, the only perfect components are the $N \gamma$ components produced by the integrated firm. Note further that $\tilde{S}$ decreases while $\tilde{S}$ aux increases with $N$.

${ }^{17}$ This is w.l.o.g.: as long as there is a finite number of bargaining rounds or a positive time discount results go trough.

${ }^{18}$ One could find intuitive to set the outside option of a component supplier inversely proportional to $s(i)$. However this contrasts with the discussion about breach of contract provisions and specificity modeling. See footnote 7 for more on this.

${ }^{19} \mathrm{~A}$ related but different issue is that of different bargaining powers, on which see Schmitz (2013).
} 
Kalai (1977) deals with group aggregation of players in multi-players Nash bargaining problems and, loosely speaking, suggests that a group be weighted by the number of its components. This implies that a group-player enjoys a share of the pie proportional to its relative size. ${ }^{20}$ In the example just presented the outcome would be that the integrated firm obtains $\frac{2}{3}$ of the pie while the non-integrated firm retains $\frac{1}{3}$, thereby keeping the shares proportional to the number of aggregated firms and avoiding a prize or a penalty to integration itself.

I follow Kalai (1977) and assume that the integrated firm has Nash weight of $N$. This implies that integration per se does neither decrease nor increase a firm's bargaining power. Instead, in my model the division of the surplus will only be affected by the outside options of integrated and non-integrated firms - which, in turn, depend on the endogenous integration decision.

Given the model outlined above, it is immediate to verify that, absent integration, a firm of type $i$ obtains a "private" revenue equal to $\pi[1-s(i)]$ plus an equal share ${ }^{21}$ of the bargained revenue through Nash bargaining from investing. Its profit can be written as:

$$
\pi\left[1-s(i)+\int_{0}^{1} s(j) d j\right]
$$

which is positive for any firm and increasing in $\pi$. It follows from (4) that firms with the least specific investment (high $i$ ) will be more profitable than firms with more specific investment because they are less exposed to hold-up.

Suppose instead that an assembler buys a subset $I \subseteq[0,1]$ of firms with Lebesgue measure $N$ and merges them into a vertically integrated company. Then his revenue is:

$$
\Pi_{A} \equiv \pi(1-N+\gamma N) \int_{i \in I}[1-s(i)] d i+F(N) \tilde{S}
$$

where $F(N)$ is the assembler's share of the bargained surplus and will be derived later. The first element is the revenue which is not subject to hold-up and is larger the lower the specificity $s(i)$ of the merged suppliers $i \in I$. The second term is the share of the bargained surplus which the assembler can appropriate through bargaining.

The surplus share of the $1-N$ non-integrated suppliers is now $1-F(N)$. And, because they are all identical at the bargaining stage, each of them earns an equal

\footnotetext{
${ }^{20}$ More precisely Kalai (1977) drops the symmetry axiom and shows that symmetric multi-person games with types -here integrated vs. non integrated suppliers- can be viewed as replicas of non symmetric reduced games where the weights are given by the relative sizes of players' types.

${ }^{21}$ All the firms have zero outside option in this case. The share is 1 because there is a mass 1 of firms.
} 
share of that. Hence, a non-integrated supplier $j$ earns the following revenue:

$$
\Pi_{S} \equiv \pi(1-N+\gamma N)[1-s(j)]+\frac{1-F(N)}{1-N} \tilde{S}
$$

where the terms have the same interpretation as above.

Notice that the bargained revenue $\tilde{S}$ is maximized when there is no integration $(N=0)$ and decreases as $N$ increases - i.e. $\partial \tilde{S} / \partial N<0$. In fact, integration reduces profitability since integrated firms are less flexible and produce some imperfect components $(\gamma<1)$. Moreover, it is clearly larger the more efficient the integrated firm is - i.e. $\partial \tilde{S} / \partial \gamma>0$. Both effects are true regardless of the shape of $s(\cdot)$ and of the specific set $I$ of internally produced components.

The assembler's problem is to choose which and how many firms to acquire. This crucially depends on the share $F(N)$ he obtains at the bargaining stage and on the bargained surplus $\tilde{S}$. The next subsection offers a brief discussion while Section 2.3 solves the model: I will first characterized the outcome of the bargaining stage and then solve for the optimal degree of integration.

\subsection{Discussion}

Intuitively, in my model vertical integration improves the bargaining stance of integrating firms in the bargaining stage but prevents them from optimally mixing and matching component suppliers to maximize the share of perfect components when producing the final product. One immediate implication of my model is that, contrarily to most works in the literature, joint profits are not maximized under optimal vertical integration. Rather, joint profits are lower, but the integrated firm is able to improve its outside option and squeeze enough rents from non-integrated suppliers to make integration privately profitable. So, in its essence, vertical integration is made possible trough expropriation. ${ }^{22}$

It will be clear from the analysis that it is optimal to integrate over the suppliers of the most specific components. In other words those who are most exposed to expropriation at the bargaining stage have the highest incentive to integrate. In this sense vertical integration in my model can be regarded as a defensive move against expropriation by those who are more exposed: these suppliers join forces with the assembler to extract some of the rents from non-integrated suppliers.

The observation that integration always decreases welfare even though it can be privately optimal for the assembler may be disturbing. In fact, this is not necessarily

\footnotetext{
${ }^{22}$ An immediate consequence of that is that my model applies to supply chains with at least three suppliers.
} 
true when investment is endogenous: if firms can vary the amount of their investment integration can improve incentives for the integrating firms to invest because it provides a shield against expropriation at the bargaining stage. Under certain conditions the welfare gain through higher investment can offset the welfare loss from lower flexibility. ${ }^{23}$ I discuss this extension in section 4.2 .

\subsection{Analysis}

I start the analysis from Stage 3 and I solve the model backward. Consider the bargaining stage where the assembler has integrated $N$ suppliers. Integrated firm and non-integrated suppliers bargain over the revenue $\tilde{S}-$ see equation (2). As discussed above, each non-integrated supplier has an outside option of zero. The outside option of the integrated firm, on the other hand, is whatever can be obtained in the auxiliary round which occurs if an agreement is not reached in the first round. In this case the bargained revenue is $\tilde{S}$ aux — equation (3) - and the integrated firm is entitled to a share $N$ of it, as prescribed by Nash bargaining $\grave{a}$ la Kalai. Thus, the outside option of the integrated assembler in the first round is

$$
N \tilde{S}^{\text {aux }}=\pi N^{2} \gamma \int_{0}^{1} s(i) d i
$$

Since the integrated firm has a better outside option than the non integrated suppliers, the assembler can secure a share of revenue in the first round, $F(N)$, which exceeds its share of production $N$. Formally, the assembler's share of bargained revenue, $F(N)$, solves the following Nash maximization problem:

$$
F(N)=\arg \max _{\varphi}\left\{\ln \left(\varphi \tilde{S}-N \tilde{S}^{\text {aux }}\right)^{N}+(1-N) \ln \left(\frac{1-\varphi}{1-N} \tilde{S}\right)\right\}
$$

The second term in this expression describes the division of revenue among the $1-N$ non-integrated firms, each one receiving an equal share of the revenue not assigned to the assembler, $1-\varphi$. The revenue share of the assembler is thus:

$$
F(N)=N+\frac{\gamma N^{2}(1-N)}{1-N+\gamma N}
$$

\footnotetext{
${ }^{23}$ Another reason why vertical integration can be welfare improving is the standard argument that, when pricing is endogenous, integration reduces the negative externality caused by double marginalization (see Tirole (1988)). This is not the case here because the demand side is not modeled.
} 
Clearly $F(N)>N$ : there is a bargaining premium which comes with integration. Also, $F^{\prime}(N)>0$ with $F(0)=0$ and $F(1)=1$. The share of revenue of the assembler does not depend on the set of suppliers he acquires, $I$, nor on the shape of the specificity function $s(\cdot)$, but solely on the number of integrated suppliers $N$ and on the inefficiency parameter $\gamma$. The intuition for this result is as follows. First, notice that the bargained surplus in the auxiliary round $\tilde{S}^{\text {aux }}$ - and, a fortiori, the assembler's outside option in the first negotiation round, $N \tilde{S}^{\text {aux }}$ — does not depend on which components are produced internally or supplied through fringe suppliers. Hence, it is only the size of the integrated firm which affects its share of bargained revenue and not the type of components produced. Second, the bargained surplus in the first $(\tilde{S})$ and the auxiliary round $\left(\tilde{S}^{\text {aux }}\right)$ are both proportional to $\int_{0}^{1} s(i) d i$, which explains why the specificity function does not affect the share of the surplus accruing to the assembler. Finally, the asymmetry of outside options between an integrated assembler and non-integrated suppliers favors the former and implies $F(N)>N$.

Notice further that $F(N)$ evaluates at $N$ when $\gamma=0$ and increases with $\gamma$. Both results hinge on the way $\gamma$ affects the outside option of the assembler. If $\gamma=0$ the outside option of the integrated firm is no better than that of separated suppliers - i.e., it is equal to zero. Hence, the integrated firm enjoys a revenue share just proportional to its relative size $N$ - as prescribed by Nash bargaining à la Kalai. As $\gamma$ increases, the outside option of the assembler becomes larger because he contributes an intermediate good of greater value in the auxiliary round if negotiations break up at the first round - i.e., $\partial \tilde{S}^{\text {aux }} / \partial N>0$. This strengthens his threat point in the first round, which allows him to extract a larger share of the bargained surplus, $\tilde{S}$.

Figure 1 illustrates the power balances resulting from vertical integration. The $s$ shape curve indicates, for each $N$, the share of the corresponding vertically integrated firm, $F(N)$. The figure presents the example of a vertically integrated firm of size $N^{\prime}$ - i.e. producing $N^{\prime}$ components in-house. Under non integration each firm has a share of one. When there is a vertically integrated firm, its share is $F\left(N^{\prime}\right)>N^{\prime}$ : thus, the 'fictitious' share of an integrated supplier, $j \equiv F\left(N^{\prime}\right) / N^{\prime}$, is larger than one $^{24}$, while the share of a non-integrated supplier, $k \equiv\left[1-F\left(N^{\prime}\right)\right] /\left(1-N^{\prime}\right)$, is lower than one.

Moving backward, I briefly comment on the contracting stage of the game. At this stage the vertically integrated firm and the non-integrated suppliers may sign a long term contract for the supply of the components of the final good. As discussed

\footnotetext{
${ }^{24}$ Notice that this is a hypothetical exercise: obviously no firm has a share larger than one and the sum of all shares is clearly one. The apparent paradox only underlines the fact that the vertically integrated firm enjoys a disproportionately large share of revenue.
} 


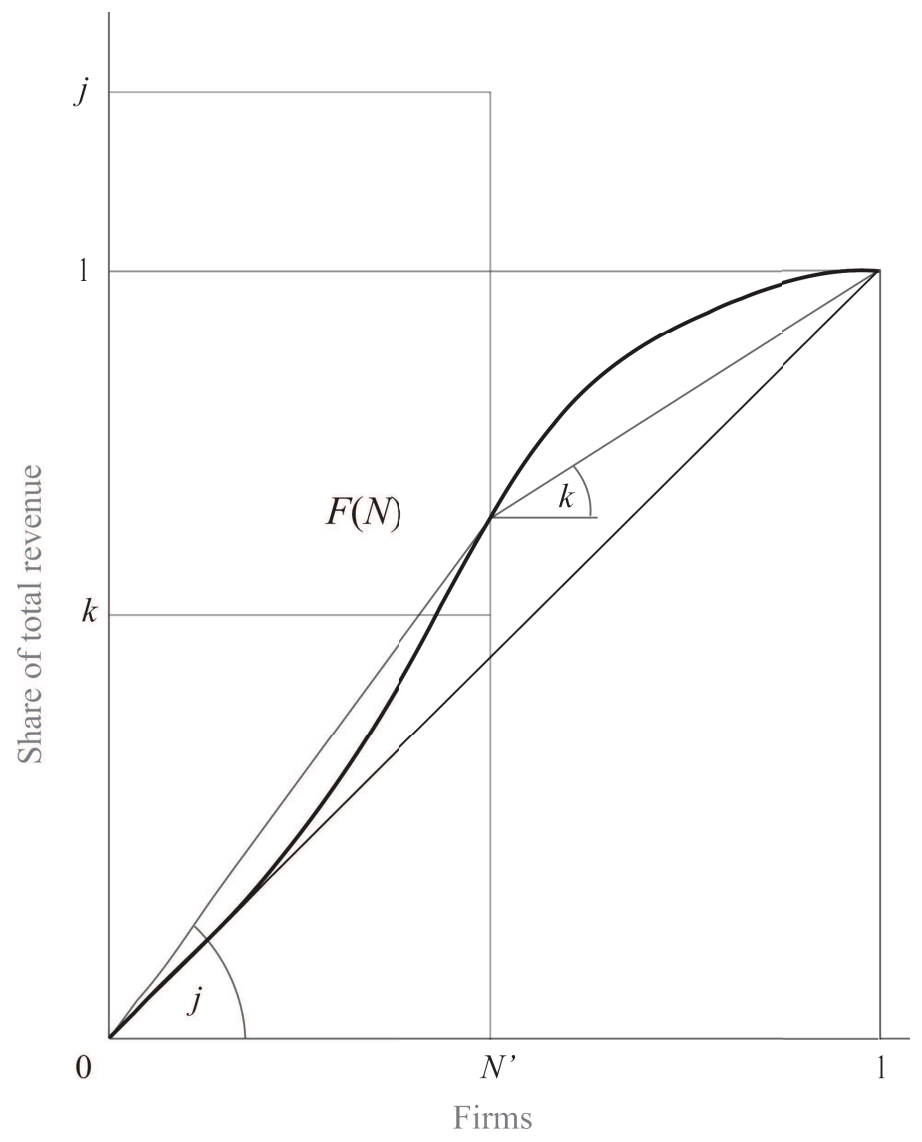

Figure 1: $F(N)$, Revenue Shares under Vertical Integration

in Section 2.1, suppliers can produce $1-N$ perfect components while the assembler can produce $\gamma N$ perfect components. A profit is anticipated in the subgame if a contract is signed, while production is not possible and profits are nil otherwise. Hence, a contract is signed.

\subsubsection{Linear specificity}

I can now turn to the analysis of the initial stage of the game in which a vertical integration decision is made. I first consider the simple benchmark case of linear specificity, in which $s(i)=1-i$. This case is particularly tractable. I will later generalize the specificity function to grasp more intuition on the relationship between relevant characteristics of an industry and the incentives to vertically integrate chunks of the supply chain. 
Suppose an assembler acquires a subset $I \subseteq[0,1]$ of firms with Lebesgue measure $N$ and merges them into an integrated company. Then, under linear specificity the bargained revenue (2) becomes:

$$
\tilde{S}=\pi(1-N+N \gamma) \int_{0}^{1}(1-i) d i
$$

where $N$ is the number of suppliers bought by the assembler. Recall that he bargained revenue is maximized when there is no integration $(N=0)$, decreases as $N$ increases — i.e. $\partial \tilde{S} / \partial N<0$ - and is larger the more efficient the integrated firm is - i.e. $\partial \tilde{S} / \partial \gamma>0$

The assembler's problem is twofold: he must choose which firms to buy and how many. The answer to the first question is intuitive: an assembler should start buying firms from the one with the highest specificity, that is the one with the least 'private' revenue. In fact, buying a firm has two consequences at the margin. First, it improves the outside option of the vertically integrated firm. This effect is independent of the type of firm bought. Second, it reduces productivity (which is $\pi(1-N+N \gamma$ ) with $\gamma<1)$ : this effect has a different impact on the assembler's revenue depending on the firms he has already bought. The more the firms already bought are exposed to expropriation, the more the damage is shared with non-integrated firms and thus attenuated, and vice versa. Hence, by first buying firms with the least 'private' investment the assembler minimizes the expected loss from buying further firms. In other words, buying first high specificity firms maximizes the marginal profit of the assembler for each firm he buys.

Hence, if an optimal degree of vertical integration $N$ exists, then the assembler produces internally the $N$ most specific components and optimally buys a portfolio $I=[0, N]$ of firms. ${ }^{25}$ His revenue (5) becomes:

$$
\Pi_{A}=\pi(1-N+\gamma N) \int_{0}^{N} i d i+F(N) \tilde{S}
$$

The answer to the second question - how many? — is simple: the assembler buys component firms until the marginal revenue from buying an extra firm is equal to its cost. The cost of a firm is the equilibrium profit the firm would derive from remaining non-integrated, which is what it would obtain bargaining ex-post if it refused to be bought ex-ante. This is equation (6) and, in the linear specificity case, it is:

$$
\Pi_{S}=\pi(1-N+\gamma N) i+\frac{1-F(N)}{1-N} \tilde{S}
$$

\footnotetext{
${ }^{25}$ Recall that the smaller $i$ the higher the contributed revenue $s(i)$ - i.e., the higher the specificity of a supplier's investment.
} 
Thus, the problem of the assembler is solved by the condition $\frac{\partial \Pi_{A}}{\partial N}=\left.\Pi_{S}\right|_{i=N}$, which is:

$$
\frac{\partial}{\partial N}\left(\pi(1-N+\gamma N) \int_{0}^{N} i d i+F(N) \tilde{S}\right)=\pi(1-N+\gamma N) N+\frac{1-F(N)}{1-N} \tilde{S}
$$

where the left hand side is the derivative of $\Pi_{A}$ with respect to $N$ with $F(N)$ as in (8) and the right hand side is $\Pi_{S}$ for the marginal firm $i=N$, as discussed above.

The following proposition holds for the linear specificity model:

Proposition 1. Assuming A1 and A2, there exists a unique equilibrium as long as $\gamma>1 / 3$. The optimal set of firms integrated by the assembler is $I=\left[0, N^{*}\right]$ with $N^{*}=\frac{3 \gamma-1}{1+\gamma}$.

Proposition 1 establishes that the equilibrium features some degree of integration as long as integration does not cause too much inefficiency. In particular, it is optimal for firms with a highly specific investment to become part of an integrated company. In fact, such firms are the ones which suffer the most from expropriation in the bargaining game. By the same token, these firms are less affected by efficiency losses, because, by contributing more to the bargained revenue, they also split most of the loss with the firms they bargain with. Therefore, the assembler has a stronger incentive to integrate high specificity firms first. In this way he realizes the bargaining premium at the minimum efficiency cost.

In this basic version of the model the optimal degree of integration solely depends on the inefficiency of the integrated firm, $\gamma$ : this is because I have constrained the specificity function to a very simple specification. In the next section I introduce a two-parameters specificity function which allows me to model the supply chain in a more flexible way. This, in turn, allows to study how the technological characteristics of an industry affect its vertical structure.

For now, however, it is useful to notice the following:

Corollary 1. When large organizations are more efficient - i.e., $\gamma$ is large - the optimal degree of vertical integration is higher and vice versa.

\subsubsection{General specificity functions}

I next consider the following two-parameter family of specificity functions:

$$
s(i)=(1-\alpha)\left(1-i^{\beta}\right),
$$




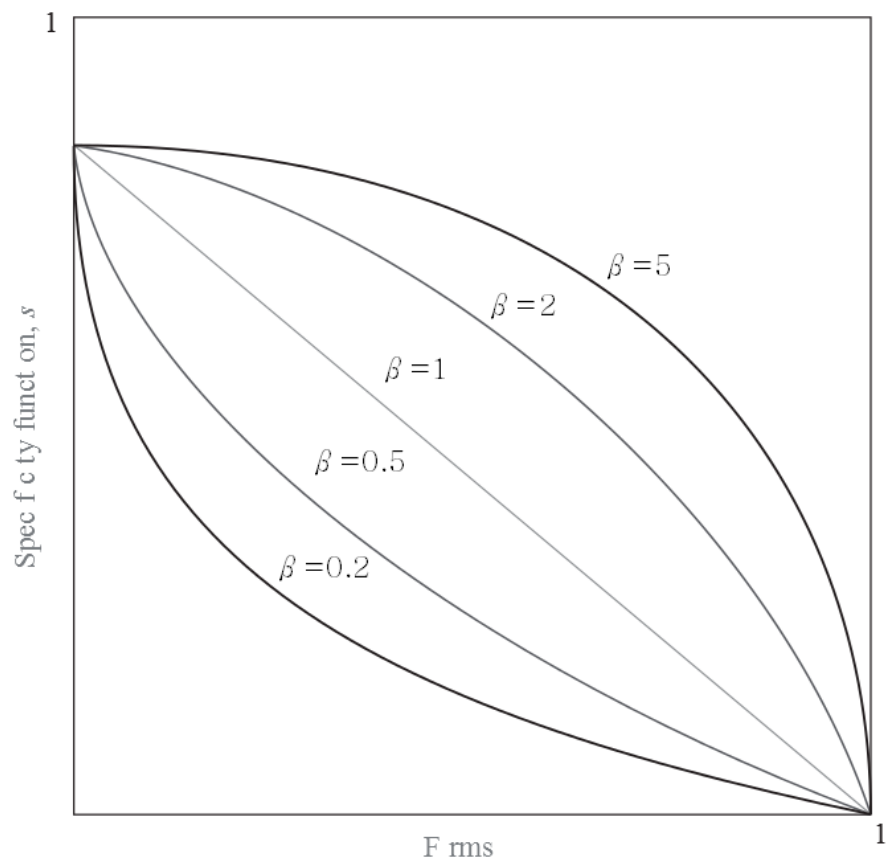

Figure 2: General specificity functions: $\alpha=0.2$ and $\beta=0.2 ; 0.5 ; 1 ; 2 ; 5$

where $0 \leq \alpha<1$ and $\beta>0$. Figure 2.3.2 offers a graphical representation.

The parameters $\alpha$ and $\beta$ summarize the state of technology in an industry and have intuitive interpretations. The parameter $\alpha$ is related to the average specificity of an industry while $\beta$ captures differences in the distribution of specificity types across the supply chain.

More precisely, the parameter $\alpha$ is a scale factor: for given $\beta$, an increase in $\alpha$ reduces the average specificity of the supply chain by the same amount - i.e., $\partial \int_{0}^{1} s(i) d i / \partial \alpha=-\beta /(1+\beta)$. In other words, $\alpha$ affects absolute, not relative specificity - i.e., $s(i) / s(j)$ does not depend on $\alpha$. Hence, I regard this parameter as an industry wide characteristic. In particular, I relate $\alpha$ to the maturity of an industry and to how innovative it is. In fact, innovative products typically require quite specific investments which likely expose producers to hold-up problems. Hence, the more innovative an industry is, the lower $\alpha$ and vice versa. Similarly, a mature industry has likely gone through the standardization of once innovative products and the value added by components in a mature industry is likely to be easier to verify. Hence, the more mature the industry, the milder the hold-up problem, the higher $\alpha$.

The parameter $\beta$ is a measure of the skewness of the specificity function along the supply chain. If $i<j$ so that component $i$ requires a more specific investment 
than component $j$, then the relative specificity $s(i) / s(j)$ diminishes as $\beta$ increases and vice versa when $i>j$. Another way to think about $\beta$ is that, as it takes values more an more distant from 1 , the specificity profile of the supply chain becomes more and more skewed. In particular, if $\beta>1$ then the number of components requiring highly specific investment is relatively large, while it is relatively small when $\beta<1$. In practice, the more sophisticated a product or the higher its technological content, the more likely it is that a relatively large number of its components requires specific investments. Hence, I associate to a high $\beta$ industries producing high tech, relatively complex products, while standard, simple goods tend to be produced by industries characterized by a low $\beta .^{26}$

Figure 2.3.2 gives a rough classification of industries based on $\alpha$ and $\beta$ according to the interpretations just given. It shows that an industry may be characterized by the general degree of specificity $\alpha$ - which in turn may depend on economy-wide or industry-specific characteristics such as maturity and innovation - as well as by the relative complexity of the final good being produced, $\beta$. The simple scheme reported in Figure 2.3.2 is clearly not exhaustive but is a useful starting point in the discussion of Section 3.

Before turning to the comparative statics suggested by the general specificity function just introduced, the next proposition extends the existence result to the new environment.

Proposition 2. Assuming $\mathbf{A} 1$ and $\mathbf{A 2}$, there exists a unique optimal degree of vertical integration $N^{*}>0$ with $I=\left[0, N^{*}\right]$ as long as $\gamma>\tilde{\gamma}$, with:

$$
\tilde{\gamma} \equiv \frac{\alpha+\beta}{\alpha+\beta(3-2 \alpha)} \in(0,1) .
$$

Proposition 2 establishes uniqueness of the optimal degree of integration under the general specificity function (9). A closed-form expression for $N^{*}$ cannot be given because the generic exponential $\beta$, while convenient in comparative statics, makes it impossible to explicitly solve for the optimal level of integration.

Moreover, the proposition provides a necessary and sufficient condition on $\gamma$ for the existence of a vertically integrated firm. In particular, $\tilde{\gamma} \in(0,1)$ and it is increasing in $\alpha$ and decreasing in $\beta$. Intuitively, the minimum efficiency for the existence of an integrated firm, $\tilde{\gamma}$, is higher when the average degree of specificity along the supply chain is lower. In fact, integration allows to recover some of the expropriated

\footnotetext{
${ }^{26}$ Notice that the link between specificity/hold-up and technology intensity is standard in the literature - see, e.g. Acemoglu, Aghion, Griffith, and Zilibotti (2010) among others.
} 


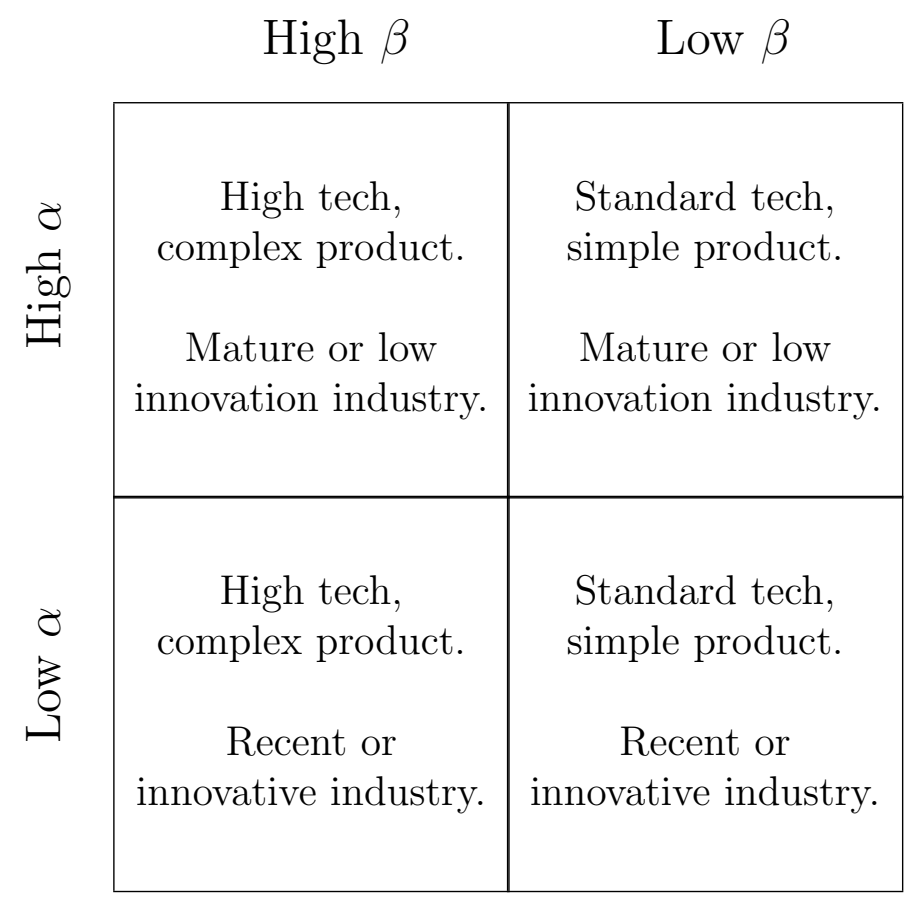

Figure 3: Simple industry classification

surplus at the cost of an efficiency loss: as the surplus to be recovered diminishes (higher $\alpha$ and lower $\beta$ ) the efficiency cost which makes integration profitable must also decrease $(\tilde{\gamma}$ grows larger).

Having generalized the result of Proposition 1, a natural question to answer is how the equilibrium $N^{*}$ responds when the specificity profile of the supply chain changes - i.e., $\alpha$ and $\beta$ vary. An industry with larger $\alpha$ uses a production technology that, on average, requires less specific investments. One would expect that, as an industry matures, technologies become more standard and widespread, reducing the average specificity of investments, i.e. $\alpha$ increases. Intuitively, lower average specificity makes integration less profitable because the hold-up problem is reduced. The next proposition confirms this intuition:

Proposition 3. Industries with lower average specificity (higher $\alpha$ ) are less integrated, i.e. $N^{*}(\alpha)$ is decreasing in $\alpha$.

The parameter $\beta$ governs the shape of the distribution of specificity across firm types. When $\beta=1$ the specificity function is uniformly distributed between $(1-\alpha)$ 
and 0 . An increase (resp. decrease) in $\beta$ corresponds to relatively more firms having high (resp. low) specificity. Intuitively, this correlates with a more complex production process. Conversely, a lower $\beta$ implies that fewer firms make highly specific investments. Intuitively, we expect that sophisticated industries with complex production processes are most prone to holdup. The next proposition confirms this conjecture:

Proposition 4. The larger the number of components requiring highly specific investment for an industry (i.e. the larger $\beta$ ) the higher its degree of vertical integration, i.e. $N^{*}(\beta)$ is increasing in $\beta$.

Propositions 3 and 4 taken together suggest that the higher the degree of investment specificity within a supply chain, the more it is prone to vertical integration. In Section 3 I use these results to interpret several stylized facts which the literature has connected to vertical integration.

Finally, it can be easily shown that Corollary 1 holds in the extended model.

\section{Applications}

Vertical integration has generally diminished over the last decades (Rajan and Wulf (2006), Brynjolfsson, Malone, Gurbaxani, and Kambil (1994)). Companies have increasingly outsourced activities that were previously carried out inside the firm (Spencer (2005), Hummels, Ishii, and Yi (2001)). Firms have gained flexibility by purchasing intermediate components on the market rather than producing them inside the firm. These trends were accompanied by a deepening of financial markets and rapid growth in some developing countries. These trends have many determinants, which clearly cannot be comprehended in a single model. Nonetheless, in the following I use the model developed in section 2.3.2 to provide a unified interpretation of a variety of inter-related phenomena which have been studied in several strands of the literature on vertical integration and firms' boundaries.

Applied research and process innovation. For a given industry, advances in applied research and process innovation improve the efficiency and efficacy of existing technologies. This kind of innovation tends to give physical capital generally more flexible production capabilities: technological advances have made machinery both more responsive to production timing needs and market demand rhythms. They have also made it possible to produce less standardized goods with a comparable amount of invested capital. As an example, consider the diffusion of robotics and just-in-time plant management techniques: Nemetz and Fry (1988) point out that such flexible 
manufacturing technologies favor organizational forms with a narrow span of control, a lower number of vertical layers and a more decentralized decision making process as compared to mass production technology organizations. In the context of my model these changes are equivalent to an increase of $\alpha$, the general state of technology. In fact, such advancements reduce the costs associated to a certain technology and slowly help it spread throughout the economy, making it increasingly standard. This, in turn, implies that investment in such technology becomes less specific. In addition, it is likely that, if any, applied research decreases $\beta$ : in fact, the components which are less complex and tend to require less specific investment are easier to standardize and are therefore likely to become standard first. ${ }^{27}$ Both these effects imply a decrease of the optimal degree of vertical integration. This helps interpret some important aspects of the general trend in industries like the automotive: in such industries the introduction of more flexible production techniques has made it convenient the outsourcing of many activities to specialized firms. These in fact are now able to provide different products for different customers with a comparable amount of investment.

Financial markets. As pointed out by Rajan and Zingales (2001), another reason for why physical capital is today less crucial than in the past is the huge development of financial markets in the last decades which has made it much more viable the acquisition of machinery, the building of new plants and the investment in equipment in general. In fact, various authors (Rajan and Zingales (2001); Acemoglu, Johnson, and Mitton (2009)) have studied the relationship between vertical integration and the development of financial markets. The argument behind such studies is that more efficient financial markets tend to reduce the hold up problem and, a fortiori, the degree of vertical integration. The mere existence of efficient credit markets -the argument goes- makes hold up threads less credible because well functioning markets provide entrepreneurs with more easily accessible outside options. For instance, if a supplier threatens to withhold from production, an efficient credit market might well mean that the threatened partner is able -or at least has more chances- to buy and/or build the machinery to internally produce the missing component. In other words, "with capital easy to come by, alienable assets such as plant and equipment have become less unique" (Rajan and Zingales (2001)). This means that physical investment is less relation-specific as a consequence of more efficient financial markets. Ideally, with perfect financial markets, no hold up may be based on any asset which could be possibly borrowed. In terms of the model the

\footnotetext{
${ }^{27}$ This is not to say that the value of standardization is higher for such components. It is rather true the opposite: standardization is more valuable when products are more complex. And yet complexity makes standard setting harder to achieve.
} 
development of financial markets can be formalized as an increase of $\alpha$. Moreover, it is likely that efficient credit markets are worth most to firms producing complex products which have very specific investments. Thus, if any, $\beta$ should decrease as financial markets become more efficient. Which means that the degree of vertical integration tends to diminish as a consequence of financial development.

Industry comparison. The model predicts that complex products requiring high-tech and sophisticated machinery are produced in industries whose structure tends to be more vertically integrated. In fact, one can interpret the parameter $\beta$ as a proxy for technology intensity or complexity. A sophisticated or complex final product involves a relatively large number of sophisticated intermediate products which require investment in highly specific machinery: this corresponds to a high $\beta$ (see Figure 2.3.2). A relatively standard product, on the contrary, involves relatively fewer complex stages of production, with less specific investments: this corresponds to a small $\beta$. Thus, technology intensive products will be produced by more integrated industries than standard products. Evidence of the above is very neatly provided by Novak and Eppinger (2001) who explicitly test the hypothesis that product complexity and vertical integration are complements. More evidence has been provided by Wilson (1977) who finds that licensing is more attractive the less complex the good involved is, and by Kogut and Zander (1993) whose results show that the probability of internalization is lower the more codifiable, teachable, and the less complex the technology is.

US auto parts and Japanese keiretsu. Various authors (Spencer and Qiu (2001); Qiu and Spencer (2002)) have studied the case of the Japanese keiretsu and the reluctance of such conglomerates to import auto parts from abroad. They stress the fact that the Japanese import only parts of limited technological content, such as seat covers. The model presented in this paper predicts this phenomenon. In fact, the model gives a rationale for why the most complex and technology intensive parts of a production process should be produced internally. Those parts, in fact, are the ones which require the most specific investments and which therefore will be carried out by the vertical integration. Which, in the context of the Japanese automotive industry, is the keiretsu itself. Only the less sophisticated parts are produced by non-integrated firms and therefore can be imported.

Trade patterns. Some authors (Vernon (1966); Antràs (2005)) have explained the pattern which leads firms to produce certain parts first internally, then in regime of FDI and finally outsourcing them to less developed countries. In particular, Antràs (2005) gives a Property Rights interpretation of such pattern. The model presented here can be used to rationalize the pattern by assuming that $a$ ) there is a (labour) cost advantage of poor countries $(\mathrm{P})$; that $b$ ) rich countries $(\mathrm{R})$ have a technological 
supremacy which reduces over time as poor countries develop; and that $c$ ) there is technological progress ${ }^{28}$ and product standardization over time. Suppose there are four periods.

$\boldsymbol{t}=\boldsymbol{O}$ The product is invented in $\mathrm{R}, \mathrm{P}$ has no skills and cannot produce. All production is in $\mathrm{R}$ and, given technology, the optimal degree of vertical integration is $V I$. The rest is produced in regime of domestic outsourcing

$\boldsymbol{t}=1 \mathrm{P}$ develops, it becomes able to produce some parts: the firm in $\mathrm{R}$ buys some standard pieces from $\mathrm{P}$ in foreign outsourcing regime

$\boldsymbol{t}=2 \mathrm{P}$ develops further, it can produce more complex parts which are critical to the firm: these are produced in regime of FDI and the firm operates directly in $\mathrm{P}$

$\boldsymbol{t}=3$ Technology evolves: (some of) the parts produced in FDI are sufficiently standard - no longer critical — to be bough outside the firm, hence the move from FDI to outsourcing

The pattern just described is only a plausible example but many other patterns could arise. It is depicted in Figure 4 where the horizontal lines represent the spectrum of firms aligned from the most specific to the least, with the vertical integration in bold.

Examples revisited: IBM vs. Apple. Consider the PC industry in the 1980s. The final good is a working $\mathrm{PC}$ - i.e., a machine equipped with a suitable operative system. The $\mathrm{PC}$ is made up of sophisticated components, many of which require a good deal of R\&D investments. The OS is certainly one of the most productspecific features of a PC. The model predicts that the assembler's optimal strategy is to retain control over it: Apple acted according to the normative prescription of the model, IBM did not. Apple survived the tough competition of those years. IBM lost power vis-à-vis Microsoft which cannibalized most of the profits prom PC making eventually forcing IBM out of business. The model clearly does not explain in full such a complex historical pattern, but highlights one of the key differences between the integration strategies of Apple and IBM which certainly contributed to the different fortunes of these companies.

Examples revisited: Cell-Phone Industry. The external (hedonic) design and the software are the most identifying and specific components of a cell-phone:

\footnotetext{
${ }^{28}$ In particular applied research and process innovation may reduce the importance of high tech, critical inputs with the age or maturity of the final good as in Antràs (2005).
} 


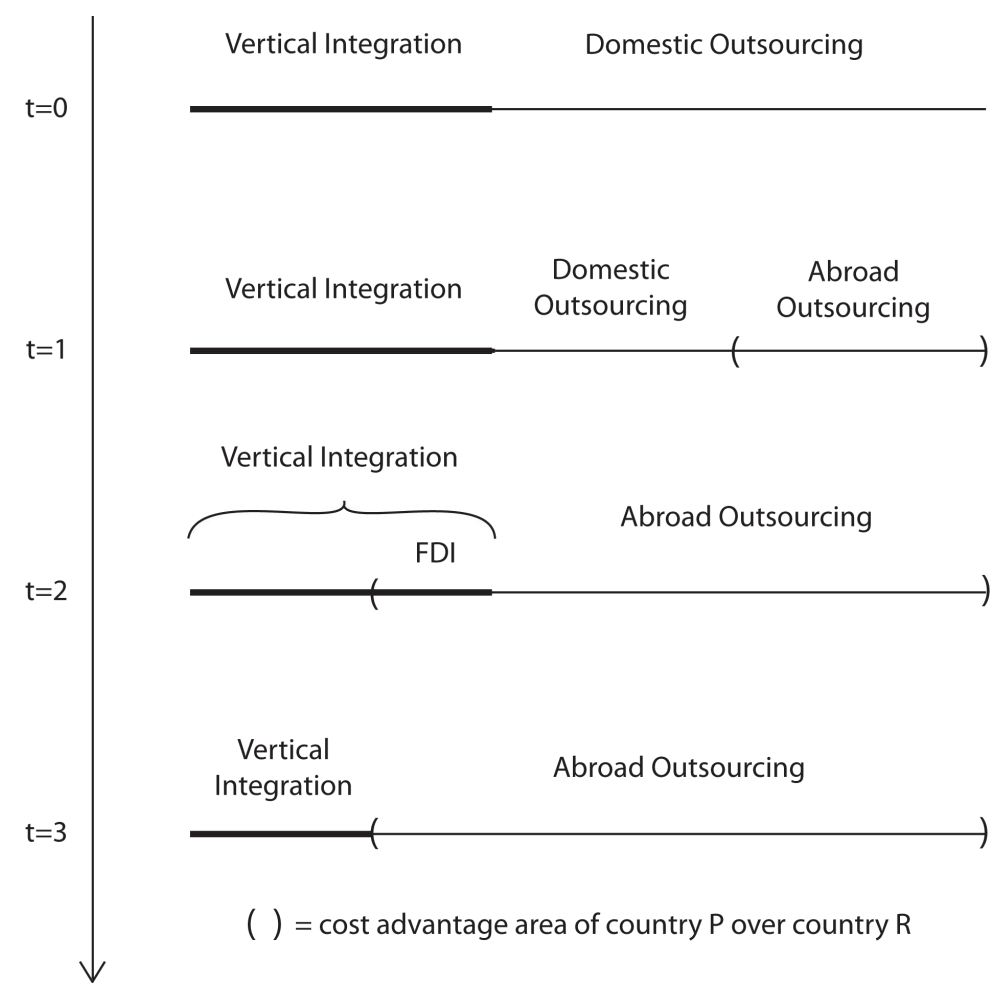

Figure 4: FDI and outsourcing

hence the model dictates that they should be made in-house. Under competitive pressure in the 1990s mobile phones companies outsourced probably more than they should have done. In terms of the model the fact that they came back to internal production in the early 2000s suggests that they run into a strategic mistake: they seem to have realized that they had acted as if the industry had higher $\alpha$ and/or a lower $\beta$ than it was actually the case. In other words, in the nineties the outsourcing of some critical chunks of the supply chain has exposed the original equipment manufacturers to fierce hold-up from the non-integrated suppliers. This has been corrected in the early 2000s by optimally expanding the degree of integration over the supply chain. 


\section{Extensions}

\subsection{Multiple Assemblers}

The model introduced in Section 2 features one assembler deciding how far to integrate along the supply chain. However, in some industries supply chains may be more articulated: there can be, for instance, specialist companies providing single components alongside midstream integrated companies which supply somewhat complex intermediate goods to a possibly integrated downstream assembler. More generally, there can be more 'vertical clusters' in a supply chain, each one sub-assembling components along the chain and contributing to the final assembly of the end product. A natural question arises: what happens when more companies can integrate over different sector of the same supply chain? In this section I extend the linear specificity model of Section 2.3.1 to accommodate for a second assembler. ${ }^{29}$

To formalize the possibility of a second integrated assembler I shall assume that there is an intermediate assembler, $A_{2}$, who produces an intermediate good using several internally produced components, and a final assembler, $A_{1}$, who also produces an intermediate good, but, in addition, is responsible for assembling the intermediate good produced by $A_{2}$ with her own and the single components provided by nonintegrated suppliers. Thus, $A_{1}$ and $A_{2}$ are vertically integrated firms within the same supply chain with the latter being a supplier of the former. ${ }^{30}$ More importantly, a component supplier may stay non integrated or be integrated by just one assembler: to put it differently, the assemblers cannot integrate over the production of the same components and vertical integration implies exclusive dealing.

Let's proceed with the analysis starting from the last stage and going backward. At the bargaining stage, assumptions A1 and A2 hold unchanged. However, the surplus shares of $A_{1}$ and $A_{2}$ depend now on the degree of integration of both assemblers, i.e. $F_{1} \equiv F_{1}\left(N_{1}, N_{2}\right)$ and $F_{2} \equiv F_{2}\left(N_{1}, N_{2}\right)$. The shares obtain as in equation (7) and their derivation is relegated to the appendix for brevity.

We now focus on the make or buy decision, Stage 1 of the game. Suppose that two assemblers, $A_{1}$ and $A_{2}$, simultaneously choose the sets of suppliers they propose to integrate with, $I_{1}$ and $I_{2}$ with measure $N_{1}$ and $N_{2}$ respectively. The "integrate the most specific suppliers" argument applies here slightly modified: an assembler, given the other assembler's integration decision, will integrate over the most specific

\footnotetext{
${ }^{29}$ Note that extending the model with a general specificity function characterized in Section 2.3.2 to multiple assemblers proves mathematically too hard to solve and adds relatively little intuition vis-à-vis the simpler linear specification of Section 2.3.1.

${ }^{30}$ Indeed, it is indifferent who is the final assembler. The only things which matter are the relative size and compositions of the assemblers.
} 
suppliers which are not integrated with the other assembler. Thus, in equilibrium, the $N_{1}^{*}+N_{2}^{*}$ most specific firms will be merged into the integrated firms $I_{1}^{*}$ and $I_{2}^{*}$.

The presence of multiple assemblers opens the door to equilibrium multiplicity. In particular, a key equilibrium feature arises: the "specificity mix" between $A_{1}$ and $A_{2}$, i.e. how specific is one integrated firm relative to the other in equilibrium. To see why this is relevant, notice that the equilibrium is certainly different if, say, $A_{1}$ integrates over the most specific suppliers - so that $I_{1}=\left[0, N_{1}^{*}\right]$ and $I_{2}=\left(N_{1}^{*}, N_{1}^{*}+N_{2}^{*}\right]$ - or, vice versa, $A_{2}$ is more specific - so that $I_{2}=\left[0, N_{2}^{*}\right]$ and $I_{1}=\left(N_{2}^{*}, N_{2}^{*}+N_{1}^{*}\right]$. These are the two extreme cases. But, in principle, there are infinite combinations with which $A_{1}$ and $A_{2}$ can integrate over the set $\left[0, N_{1}^{*}+N_{2}^{*}\right]$ of suppliers in equilibrium.

It is therefore useful to parametrize the equilibrium outcome in order to analyze it. One way to do this is to model a 'generic' equilibrium as a mixture between the extreme cases just mentioned. In other words, take an equilibrium in which $N_{1}^{*}+N_{2}^{*}$ components are produced by the vertically integrated assemblers and the outcome " $A_{1}$ produces the $N_{1}^{*}$ most specific components" happens with (exogenous) probability $\kappa$ while the outcome " $A_{2}$ produces the $N_{2}^{*}$ most specific components" happens with complementary probability. Then, the privately "appropriable" revenues of $A_{1}$ and $A_{2}$ (the first addendum in square brackets of equation (5), page 10) are:

$$
\begin{aligned}
& \pi\left(1-\left(N_{1}+N_{2}\right)(1-\gamma)\right)\left(\kappa \int_{0}^{N_{1}} i d i+(1-\kappa) \int_{N_{2}}^{N_{2}+N_{1}} i d i\right) \\
& \pi\left(1-\left(N_{1}+N_{2}\right)(1-\gamma)\right)\left((1-\kappa) \int_{0}^{N_{2}} i d i+\kappa \int_{N_{1}}^{N_{1}+N_{2}} i d i\right)
\end{aligned}
$$

where $0 \leq \kappa \leq 1$ is the mixing parameter. In this case $A_{1}$ is as specific as $A_{2}$ for $\kappa=1 / 2$ while $A_{1}$ is more (resp. less) specific than $A_{2}$ for $\kappa>1 / 2(\operatorname{resp} . \kappa<1 / 2$ ). The model, which is otherwise unchanged, is solved for a given $\kappa$ and is silent as to which $\kappa$ should emerge in equilibrium - i.e. selection issues are not addressed.

The mixing parameter $\kappa$ can be thought of as describing how heterogeneous assemblers $A_{1}$ and $A_{2}$ are in terms of their components' specificity. When $\kappa=1 / 2$, the specificity profiles of the assemblers are identical, when $\kappa$ is lower assembler $A_{2}$ integrates over a relatively more specific part of the supply chain, while the opposite is true when $\kappa$ is larger.

This specifications allows to characterize the equilibrium integration degrees, $N_{1}^{*}$ and $N_{2}^{*}$, as a function of the relative specificity $\kappa$ of the integrated firms, $A_{1}$ and $A_{2}$. In particular, it can be shown that:

Proposition 5. Assuming $\boldsymbol{A} 1$ and $\boldsymbol{A} 2$, let there be two assemblers, $A_{1}$ and $A_{2}$, simultaneously taking integration decisions, and let $\kappa$ be the equilibrium specificity mix. The following statements are true: 
1. a solution to the vertical integration game exists - i.e. $N_{1}^{*} \geq 0$ and $N_{2}^{*} \geq 0$ with strict inequality for at least one assembler - as long as $\gamma>\hat{\gamma}$ where:

$$
\hat{\gamma} \equiv \frac{1+2 \sqrt{\kappa(1-\kappa)}}{3}
$$

In addition, assemblers integrate both if and only if the specificity mixing is not extreme, i.e. $N_{1}^{*}>0$ and $N_{2}^{*}>0$ if and only if $0<\kappa<1$. In particular, writing $N_{i}^{*} \equiv N_{i}^{*}(\kappa)$, it holds $N_{1}^{*}(0)=0$ and $N_{2}^{*}(1)=0$. Moreover $N_{1}^{*}(1 / 2)=N_{2}^{*}(1 / 2)$.

2. there exists $\hat{\hat{\gamma}}>\frac{2}{3}$ such that, for $\gamma>\hat{\hat{\gamma}}$, the more specific an integrated assembler relative to the other, the higher his degree of integration, i.e. $N_{1}^{*}(\kappa)$ is increasing and $N_{2}^{*}(\kappa)$ decreasing in $\kappa$.

3. for all $(\gamma, \kappa) \in[0,1) \times[0,1]$ such that $N_{1}^{*}, N_{2}^{*}$ and $N^{*}$ are defined, it holds $N_{1}^{*}+N_{2}^{*}<N^{*}$ where $N^{*}$ is the equilibrium degree of integration derived in Proposition 1.

Proposition 5 extends Proposition 1 but adds some new results too. In particular point 1 demonstrates that a vertically integrated equilibrium is more difficult to sustain when there are two assemblers integrating over pieces of the supply chain: in fact, the sufficient condition from Proposition 1 is $\gamma>\frac{1}{3}$, while it is $\gamma>\hat{\gamma}$ here and it clearly holds $\hat{\gamma} \geq \frac{1}{3}$. When integration is not too inefficient, however, an equilibrium with vertical integration exists. Moreover, the equilibrium has both assemblers integrated only if their specificity profiles are not too unbalanced, i.e. $\kappa$ is neither 0 or 1 . The intuition for this result is that, if an assembler, say $A_{1}$, has integrated over the most specific component producers $(\kappa=1)$ then the other assembler finds the cost of integrating over less specific component suppliers higher than the benefit from increased bargaining power. In fact, as argued before, while the benefit of integrating a supplier does not depend on its specificity degree, the cost in terms of efficiency is higher the lower the degree of specificity. Point 2 of the proposition further characterizes the equilibrium showing that the incentive to integrate for an assembler is stronger the more specific its integration profile relative to the one of the other assembler.

A natural question addressed in Proposition 5 is the following: how does the equilibrium with multiple assemblers compare to the one with a single assembler (Proposition 1)? Can they be compared from an efficiency point of view? Point 3 reveals that competition between integrated assemblers at the bargaining stage 
reduces the equilibrium degree of (total) integration. As a consequence, given an efficiency level $\gamma$, the welfare loss is higher under a single assembler than under multiple assemblers. This latter result is true for any specificity mix between assemblers.

Finally, do equilibria respond in the same way to changes in the underlying common parameter $\gamma$ ? Corollary 2 extends the result of Corollary 1 that the optimal degree of integration increases with $\gamma$.

Corollary 2. Assuming $\boldsymbol{A} 1$ and $\boldsymbol{A} 2$, let there be two assemblers, $A_{1}$ and $A_{2}$, simultaneously taking integration decisions, and let $\kappa$ be the equilibrium specificity mix. Then:

1. the "total" degree of integration, i.e. $N_{1}^{*}+N_{2}^{*}$, is increasing in $\gamma$ for all $\kappa \in$ $[0,1]$.

2. there exist $0<\underline{\kappa}<\bar{\kappa}<1$ such that the following sufficient conditions hold:

- if $\kappa>\underline{\kappa}$ then $N_{1}^{*}(\gamma)$ increases with $\gamma$.

- if $\kappa<\bar{\kappa}$ then $N_{2}^{*}(\gamma)$ increases with $\gamma$.

Corollary 2 has an interesting feature. Point 1 generalizes the finding that a higher efficiency of vertically integrated firms induces equilibria with more integration: integration along the chain considered altogether increases, as in Proposition 1. However, the result cannot be transferred to the individual assembler tout court. In fact, it is now constrained to a range of specificity profiles $\kappa \in[\underline{\kappa}, \bar{\kappa}]$. The implication of point 2 is that an increase in the efficiency of large organizations leads an assembler to higher integration only when his integration profile has sufficiently high specificity (i.e. $\kappa>\underline{\kappa}$ for $A_{1}$ and $\kappa<\bar{\kappa}$ for $A_{2}$ ). If this is not the case, as $\gamma$ increases the assembler with the more specific profile enjoys a relatively higher benefit from more integration which induces it to integrate disproportionately more to the expenses of the assembler with a lower specificity profile. In other words, while a better efficiency strengthens both assemblers in a balanced way as long as $\kappa \in[\underline{\kappa}, \bar{\kappa}]$ so that both find it optimal to increase their integration degree, when $\kappa$ falls outside this range one assembler is advantaged compared to the other because the cost of integration is reduced dis proportionally more for the former.

\subsection{Endogenous Investment}

In the model introduced in previous sections integration is privately optimal but socially wasteful. The aggregate industry profit is greater without integration - 
when it is $\pi$ - than under integration - when it equals $\pi\left(1-N^{*}+\gamma N^{*}\right)$. This is because integrated firms are less flexible and produce more imperfect components. Integration per se only allows the assembler to capture a disproportionate share of the appropriable revenue and hence is equivalent to a welfare-neutral redistribution. This is in contrast to standard results in the IO literature (see, e.g., Tirole (1988) for a typical double marginalization argument which pushes in the opposite direction).

However, by fixing the level of investment for all firms my model shuts down one potentially important channel through which integration might actually increase welfare. Intuitively, integrated firms can shield their investment better from expropriation. Since integrated firms make the most specific investments within an industry this might increase the willingness of the integrated company to invest in production.

A social planner might therefore allow integration because it may give rise to a socially preferable second-best equilibrium. To study this possibility I make the level of investment endogenous using a highly simplified version of the basic model of Section 2.3.1:

1. There are two types of firms only: half have completely specific investment $(r=0)$, half have not specific investment at all $(r=1)$

2. Firms can invest either 1 or 2 units of capital.

3. The profitability of investment is $\pi_{1}$ (or $\pi_{1}(1-N+\gamma N)$ ) if a firm invests 1 , while it is $\pi_{2}\left(\right.$ or $\left.\pi_{2}(1-N+\gamma N)\right)$ if it invests 2 , with $\pi_{1}>\pi_{2}>1$

4. The productivities are sufficiently large but not too close one another (in particular $\frac{2}{\gamma}<\pi_{1}<\frac{7}{3}$ and $\left.\frac{\pi_{1}}{2}+\frac{1}{2 \gamma}<\pi_{2}<\frac{\pi_{1}}{2}+1\right)$

Under the above assumptions the following holds:

Proposition 6. If $\gamma$ is close enough to 1, then the following statements are true:

1. Under non integration high specificity firms invest 1 and low specificity firms invest 2

2. The equilibrium is characterized by full integration $\left(N^{*}=1\right)$

3. In equilibrium the assembler invests 2 in all the divisions of the vertically integrated firm

4. The total profit of the industry is greater in the integrated equilibrium than under non integration 
Proposition 6 demonstrates that integration is not necessarily detrimental to welfare. In fact, by providing a protection against revenue expropriation, integration can provide greater incentives to invest. In some cases, as shown in the proposition, this is sufficient to overcome the efficiency loss caused by integration and, consequently, integration can enhance welfare.

\section{Conclusion}

I have presented a theory of vertical integration which explains why and to what extent firms in an industry become vertically integrated. The perspective of this paper emphasizes the bargaining problem associated to the vertical integration decision rather then the incentives to invest. As such, it is not mutually exclusive with the prevalent Grossman-Hart-Moore perspective but rather complementary.

My model predicts that integration is the privately optimal response of a subset of firms to their investments being appropriated by other firms with less specific investments. Integration is viewed here as a means to gain bargaining power with respect to non-integrated firms. The context is a relationship between an assembler and several suppliers which contribute towards the production of a final good and which expropriate each other's revenue because their investments are specific to the relationship. Integration is the ex-ante optimal response of an assembler who has to decide how much production to do in-house. He optimally integrates the firms more exposed to expropriation in the ex-post bargaining problem: by merging them into a larger organization he gains bargaining power and enjoys a disproportionately larger share of the total appropriable revenue. This happens at the cost of foregone flexibility: the assembler is no longer able to choose the best suppliers for its final good.

This paper views vertical integration as an optimal economizing strategy in the presence of asymmetric exposure to expropriation: firms which are more exposed to expropriation benefit the most from the increased power provided by integration. As Williamson (1979) pointed out, there is, in the real world, a continuum of specificity degrees: as the degree of specificity increases, the market becomes less and less feasible for some firms and integration becomes a better response to the hold-up problem. Coherent with a view which regards the market as the optimum, the model displays a welfare loss in any equilibrium which involves integration. This is confirmed by the finding that whenever more assemblers are allowed to integrate over the same supply chain, the ensuing dilution of bargaining power tends to restore efficiency.

However, the paper also considers the effect of integration on incentives and 
demonstrates that there are conditions under which integration is indeed welfare improving. In fact, by providing a shield against expropriation, integration improves the incentive to invest of the assembler. In an extension of the model where firms are allowed to vary the size of their investment it is shown that, under certain conditions, the shield provided by integration leads to more investment and to a higher welfare.

The paper also illustrates in which sense the technological development of the several past decades might have impacted the organizational structure of firms causing a wave of externalizations and a surge in outsourcing strategies. I argue that process innovation has made capital less specific over time reducing the average degree of specificity of a given industry. This has made integration less valuable over time determining the observed pattern of organizational structures.

Finally, the model offers a key to interpret the different propensity to vertically integrate in different industries. I argue that when a majority of the stages of a production process involve highly specific investments then it will be observed a more vertically integrated organization of production and vice versa. 


\section{References}

Acemoglu, D., P. Aghion, R. Griffith, and F. Zilibotti (2010): "Vertical Integration and Technology: Theory and Evidence," Journal of the European Economic Association, 8(5), 989-1033.

Acemoglu, D., P. Antràs, And E. Helpman (2007): "Contracts and technology Adoption," American Economic Review, 97, 916-943.

Acemoglu, D., S. Johnson, and T. Mitton (2009): "Determinants of Vertical Integration: Financial Development and Contracting Costs," The Journal of Finance, 64(3), 1251-1290, NBER Working Paper.

Antràs, P. (2005): "Incomplete Contracts and the Product Cycle," American Economic Review, 95, 1054-1073.

Binmore, K., A. Rubinstein, and A. Wolinsky (1986): "The Nash bargaining solution in economic modelling," The RAND Journal of Economics, 17(2), 176188.

Brynjolfsson, E., T. Malone, V. Gurbaxani, and A. Kambil (1994): "Does Information Technology Lead to Smaller Firms?," Management Science, 40(12), $1628-1644$.

Coase, R. H. (1937): "The Nature of the Firm," Economica, 4(16), 386-405, New Series.

De Fontenay, C. C., And J. S. Gans (2005): "Vertical Integration in the Presence of Upstream Competition," The RAND Journal of Economics, 36(3), 544-572.

Grossman, S. J., and O. D. Hart (1986): "The Costs and Benefits of Ownership: A Theory of Vertical and Lateral Integration," Journal of Political Economy, 94(4), 691-719. 
Hart, O., And J. Moore (1990): "Property Rights and the Nature of the Firm," Journal of Political Economy, 98(6), 1119-1158.

Hart, O., And J. Tirole (1990): "Vertical Integration and Market Foreclosure," Brookings Papers on Economic Activity. Microeconomics, 1990(2), 205-286.

Hortaçsu, A., and C. Syverson (2007): "Cementing Relationships: Vertical Integration, Foreclosure, Productivity, and Prices," Journal of Political Economy, 115(2), 250-301.

Hummels, D., J. IshiI, And K.-M. Yi (2001): "The nature and growth of vertical specialization in world trade," Journal of International Economics, 54, 75-96.

IozZI, A., AND T. VALLETti (2010): "Vertical bargaining and countervailing power," .

KalaI, E. (1977): "Nonsymmetric Solutions and Replications of Two-Person Bargaining," International Journal of Game Theory, 6(3), 129-133.

Kogut, B., and U. Zander (1993): "Knowledge of the Firm and the Evolutionary Theory of the Multinational Corporation," Journal of International Business Studies, 24(4), 625-645.

Kranton, R. E., and D. F. Minehart (2002): "Vertical Foreclosure and Specific Investments," Working Paper.

Laussel, D. (2008): "Buying Back Subcontractors: The Strategic Limits of Backward Integration," Journal of Economics \& $\mathcal{G}$ Management Strategy, 17(4), 895-911.

Laussel, D., and N. V. Long (2012): "Vertical Disintegration: A Dynamic Markovian Approach," Journal of Economics \& Management Strategy, 21(3), 745771. 
Legros, P., and A. F. Newman (2013): "A Price Theory of Vertical and Lateral Integration," Quarterly Journal of Economics, 128(2), 725-770.

Macaulay, S. (1963): "Non-Contractual Relations in Business: A Preliminary Study," American Sociological Review, 28(1), 55-67.

Matsushima, N., and T. Mizuno (2012): "Equilibrium Vertical Integration with Complementary Input Markets," The B.E. Journal of Economic Analysis $\&$ Policy (Contributions), 12(1), 1935-1682.

Nemetz, P. L., And L. W. Fry (1988): "Flexible Manufacturing Organizations: Implications for Strategy Formulation and Organization Design," OMEGA Academy of Management Review, 13(4), 627-638.

Novak, S., And S. D. Eppinger (2001): "Sourcing by Design: Product Complexity and the Supply Chain," Management Science, 47(1), 189-204.

Qiu, L. D., And B. J. Spencer (2002): "Keiretsu and relationship-specific investment: implications for market-opening trade policy," Journal of Internationa Economics, 58, 49-79.

Rajan, R. G., and J. Wulf (2006): "The Flattening of the Firm: Evidence from Panel Data on the Changing Nature of Corporation Hierarchies," Review of Economics and Statistics, 88(4), 759-773.

Rajan, R. G., And L. Zingales (2001): "The Influence of the Financial Revolution on the Nature of Firms," American Economic Review, 91(2), 206-211, Papers and Proceedings of the Hundred Thirteenth Annual Meeting of the American Economic Association.

Reisinger, M., and E. Tarantino (2013): "Vertical Integration with Complementary Inputs," . 
Salinger, M. A. (1988): "Vertical Mergers and Market Foreclosure," Quarterly Journal of Economics, 103(2), 345-356.

Schmitz, P. W. (2013): "Bargaining position, bargaining power, and the property rights approach," Economic Letters, 119, 28-31.

Spencer, B. J. (2005): "International Outsourcing and Incomplete Contracts," Canadian Journal of Economics, 38(4), 1107-1135.

Spencer, B. J., and L. D. QIU (2001): "Keiretsu and Relationship-Specific Investment: A Barrier to Trade?," International Economic Review, 42(4), 871-901.

Stole, L. A., And J. Zwiebel (1996): "Organizational Design and Technology Choice under Intrafirm Bargaining," American Economic Review, 86(1), 195-222.

Tirole, J. (1988): The Theory of Industrial Organization, vol. 1 of MIT Press Books. The MIT Press.

Vernon, R. (1966): "International Investment and International Trade in the Product Cycle," Quarterly Journal of Economics, 80(2), 190-207.

Williamson, O. E. (1979): "Transaction-Cost Economics: The Governance of contractual Relations," Journal of Law and Economics, 22(2), 233-261.

(1985): The Economic Institutions of Capitalism. Free Press.

(2002): "The Theory of the Firm as Governance Structure: From Choice to Contract," Journal of Economic Perspectives, 16(3), 171-195.

Wilson, R. W. (1977): "The Effect of Technological Environment and Product Rivalry on R\&D Effort and Licensing of Inventions," Review of Economics and Statistics, 59(2), 171-178. 


\section{APPENDIX}

Proof of Proposition 1: rearranging terms, (2.3.1) becomes:

$$
F^{\prime}(N)-\frac{1-F(N)}{1-N}-\frac{1-\gamma}{1-N+\gamma N}\left(F(N)+\frac{\int_{0}^{N} i d i}{\int_{0}^{1}(1-j) d j}\right)=0 .
$$

In studying the above expression I will always assume $\gamma>0$ : technically, this makes all the involved functions continuous for each $N$ between 0 and 1; economically, it means that efficiency is not completely lost when the assembler integrates firms (if $\gamma=0$ a vertical integration cannot produce any perfect component).

The condition above, once all terms are substituted, simplifies to:

$$
N(-1+\gamma(3-N)-N)=0
$$

The LHS equals zero at $N=0$ and $-2(1-\gamma) \leq 0$ at $N=1$. Its first derivative is:

$$
-1+\gamma(3-2 N)-2 N
$$

which equals $3 \gamma-1$ at $N=0$. Therefore LHS(A1) is increasing at the origin as long as $\gamma>1 / 3$. Finally, the second derivative of $\operatorname{LHS}(\mathrm{A} 1)$ is:

$$
-2(1+\gamma)<0
$$

The considerations above imply that, for $\gamma>1 / 3$, it exists $N^{*} \in(0,1]$ such that, for $N<N^{*}$ the LHS of (A1) is positive, while for $N>N^{*}$ it is negative. Therefore $N^{*}$ is a solution to the problem of the assembler. In fact, it is the only equilibrium because at the corner solution $N=0$ the marginal revenue of buying a firm is positive. Therefore in this benchmark case the problem of the assembler (A1) has a simple closed form solution:

$$
N^{*}=\frac{3 \gamma-1}{1+\gamma} \in(0,1] \quad \text { iff } \quad \gamma \in\left(\frac{1}{3}, 1\right]
$$


Q.E.D.

Proof of Corollary 1: follows immediately from the expression for $N^{*}$. In fact, its derivative with respect to $\gamma$ is $4 /(1+\gamma)^{2}$. Q.E.D.

Proof of Proposition 2: I'll follow the same steps as in the proof of Proposition 1. Remember that $\alpha \in[0,1), \beta>0$ and, again, $\gamma>0$. The condition for $N^{*}$ is now:

$$
N(-1+\gamma(3-N)-N)+\frac{(1-\gamma) N\left(\beta N-N^{\beta}-\alpha\left(1+\beta+\beta N-N^{\beta}\right)\right)}{(1-\alpha) \beta}=0
$$

The LHS of (A2) equals 0 at $N=0$ and $-(1+\beta)(1-\gamma) /(1-\alpha) \beta \leq 0$ at $N=1$. Its first derivative with respect to $N$ is:

$$
\frac{-1}{(1-\alpha) \beta}\left[N^{\beta}(1-\alpha)(1+\beta)(1-\gamma)+2 \beta \gamma(1-\alpha)(2 N-1)+(\alpha+\beta)(1-\gamma)\right]
$$

The values of (A3) at $N=0$ and $N=1$ are:

$$
\begin{aligned}
\left.(\mathrm{A} 3)\right|_{N=0} & =\frac{-1}{(1-\alpha) \beta}[\beta+\alpha(1-\gamma)+\beta \gamma(2 \alpha-3)]>0 \text { iff } \gamma>\frac{\alpha+\beta}{\alpha+\beta(3-2 \alpha)} \\
\left.(\mathrm{A} 3)\right|_{N=1} & =\frac{-1}{(1-\alpha) \beta}[1-\gamma+\beta(2-\alpha(1+\gamma))]<0 .
\end{aligned}
$$

Therefore the LHS of (A2) is increasing at the origin as long as $\gamma$ is sufficiently large. Finally, the second derivative of LHS(A2) is:

$$
-\frac{N^{\beta}(1+\beta)(1-\gamma)+4 \gamma}{N}<0
$$

The considerations above prove that LHS(A2), as LHS(A1) in Proposition 1, is a concave function which starts out at zero and increases above zero if $\gamma$ is sufficiently large; then it decreases below zero as $N$ approaches one. At some point, it takes the value of zero which proves the existence of an equilibrium. As in Proposition 1 the corner solution $N=0$ is not an equilibrium as the marginal revenue of buying a firm is positive. Q.E.D. 
Proof of Proposition 3: We have to show that an increase of $\alpha$ implies a decrease of $N^{*}$. To this end, it suffices to show that the LHS of (A2) is decreasing in $\alpha \forall N \in[0,1]$, provided that the condition on $\gamma, \gamma>(\alpha+\beta) /(\beta(3-2 \alpha)+\alpha)$, remains satisfied. In fact, the derivative of LHS(A2) with respect to $\alpha$ is:

$$
\frac{\partial \operatorname{LHS}(\mathrm{A} 2)}{\partial \alpha}=-\frac{(1+\beta)(1-\gamma) N}{(1-\alpha)^{2} \beta(1-(1-\gamma) N)}<0,
$$

which proves Proposition 3. Q.E.D.

Proof of Proposition 4: we have to show that an increase of $\beta$ implies an increase of $N^{*}$. To this end, it suffices to show that the LHS of (A2) is increasing in $\beta$, provided that the condition on $\gamma, \gamma>(\alpha+\beta) /(\beta(3-2 \alpha)+\alpha)$, remains satisfied. In fact, the derivative of $\operatorname{LHS}(\mathrm{A} 2)$ with respect to $\beta$ is:

$$
\frac{\partial(\mathrm{A} 2)}{\partial \beta}=\frac{(1-\gamma) N\left(\alpha+N^{\beta}(1-\alpha)(1-\beta \ln (N))\right)}{(1-\alpha) \beta^{2}(1-(1-\gamma) N)}>0,
$$

which proves Proposition 4. Q.E.D.

Proof of Corollary 1 with general specificity function: It suffices to show that the derivative of (A2) with respect to $\gamma$ is positive. Indeed it is:

$$
\frac{\partial(\mathrm{A} 2)}{\partial \gamma}=N \frac{\alpha+(1-\alpha) N^{\beta}+\beta\left(1+2(1-\alpha)\left(1-2 N+N^{2}\right)\right)}{(1-\alpha) \beta(1-(1-\gamma) N)^{2}}>0 \quad \forall N>0 .
$$

Q.E.D.

Proof of Proposition 5 (sketch): instead of (2.3.1) we now have to solve the 
following system:

$$
\begin{gathered}
\frac{\partial}{\partial N_{1}}\left(\psi\left[\kappa \int_{0}^{N_{1}} i d i+(1-\kappa) \int_{N_{2}}^{N_{2}+N_{1}} i d i+F_{1} \int_{0}^{1}(1-j) d j\right]\right)= \\
=\psi\left[N_{1}+N_{2}+\frac{1-F_{1}-F_{2}}{1-N_{1}-N_{2}} \int_{0}^{1}(1-j) d j\right], \\
\frac{\partial}{\partial N_{2}}\left(\psi\left[(1-\kappa) \int_{0}^{N_{2}} i d i+\kappa \int_{N_{1}}^{N_{1}+N_{2}} i d i+F_{2} \int_{0}^{1}(1-j) d j\right]\right)= \\
=\psi\left[N_{1}+N_{2}+\frac{1-F_{1}-F_{2}}{1-N_{1}-N_{2}} \int_{0}^{1}(1-j) d j\right],
\end{gathered}
$$

where $\psi \equiv \psi\left(N_{1}, N_{2}, \gamma\right)=\pi\left(1-\left(N_{1}+N_{2}\right)(1-\gamma)\right)$, while $F_{1} \equiv F_{1}\left(N_{1}, N_{2}, \gamma\right)$ and $F_{2} \equiv F_{2}\left(N_{2}, N_{1}, \gamma\right)$ solve the following Nash Bargaining problem:

$$
\begin{aligned}
\arg \max _{\varphi_{1}, \varphi_{2}}\{ & \ln \left(\varphi_{1} \pi\left(1-\left(N_{1}+N_{2}\right)(1-\gamma)\right) \int_{0}^{1} s(i) d i-\pi N_{1}^{2} \gamma \int_{0}^{1} s(i) d i\right)^{N_{1}}+\quad \text { (A5) } \\
& +\ln \left(\varphi_{2} \pi\left(1-\left(N_{1}+N_{2}\right)(1-\gamma)\right) \int_{0}^{1} s(i) d i-\pi N_{2}^{2} \gamma \int_{0}^{1} s(i) d i\right)^{N_{2}}+ \\
& \left.+\left(1-N_{1}-N_{2}\right) \ln \left(\frac{1-\varphi_{1}-\varphi_{2}}{1-N_{1}-N_{2}} \pi\left(1-\left(N_{1}+N_{2}\right)(1-\gamma)\right) \int_{0}^{1} s(i) d i\right)\right\} .
\end{aligned}
$$

The solution to (A5), provided $N_{1}+N_{2} \leq 1$, is:

$$
F_{i}\left(N_{i}, N_{-i}, \gamma\right)=N_{i}+\gamma N_{i} \frac{N_{i}\left(1-N_{i}\right)-N_{-i}^{2}}{1-(1-\gamma)\left(N_{i}+N_{-i}\right)} \quad i \in\{1,2\}
$$

where the second term on the right hand side can now be positive or negative depending on the opponent's integration level.

Optimal integration degrees for assemblers $A_{1}$ and $A_{2}$, respectively $N_{1}^{*}$ and $N_{2}^{*}$, solve the system in (A4) where $F_{i}=F_{i}\left(N_{i}, N_{-i}, \gamma\right)$ as in (A6). A closed form solution satisfying $N_{i}^{*} \geq 0$ for $i \in\{1,2\}$ with at least one strict inequality and such that $N_{1}^{*}+N_{2}^{*} \leq 1$ exists provided $\gamma>\hat{\gamma}$ with:

$$
\hat{\gamma} \equiv \frac{1+2 \sqrt{\kappa(1-\kappa)}}{3}
$$


The closed-form solutions $N_{1}^{*} \equiv N_{1}^{*}(\kappa, \gamma)$ and $N_{2}^{*} \equiv N_{2}^{*}(\kappa, \gamma)$ as well as condition (A7) are obtained using computational software (Wolfram Mathematica 9) and are not reported as they correspond to a very large output. They are available upon request. Indeed, there are two sets of solutions, one corresponding to the black area and one corresponding to the grey area in Panel (a) of Figure 5. While a proof can

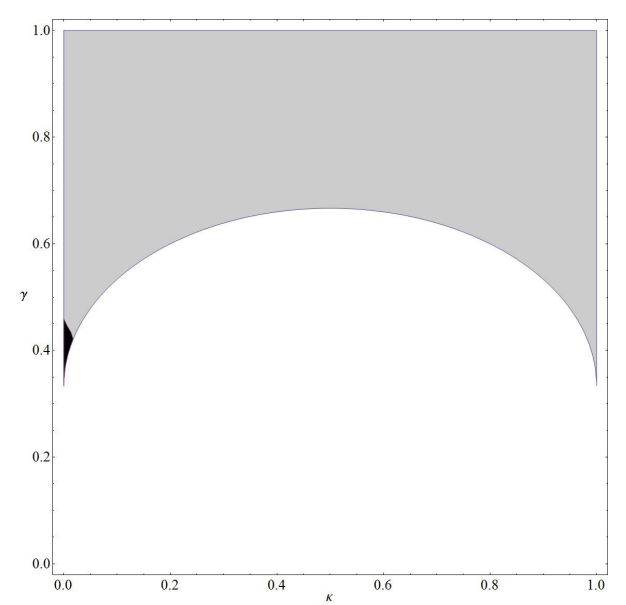

(a) Existence region

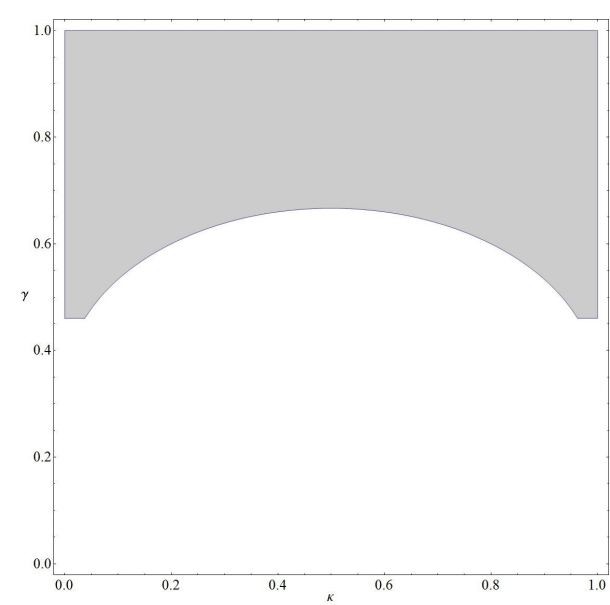

(b) Constrained region

Figure 5: regions in the parameter space $(\kappa, \gamma) \subseteq(0,1) \times(0,1)$

be made for both sets of solutions, I will focus here on the solution corresponding to the larger (grey) set of parameters. To eliminate the solution corresponding to the smaller (black) set, it suffices to restrain the attention to the pairs $(\kappa, \gamma)$ such that $\kappa \in(0,1)$ and:

$$
\gamma>\max \left[\frac{46}{100}, \frac{1+2 \sqrt{\kappa(1-\kappa)}}{3}\right] .
$$

This area corresponds to Panel (b) in Figure 5. While this cut on the parameter region is a bit rude, it nevertheless allows me to concentrate on a wide parameter region and to keep the treatment as simple as possible. From now on I concentrate on the constrained region. A proof for the 'black' region is available upon request. 
I now prove Point 2 of the Proposition. Figure 6 illustrates the regions corresponding to how $N_{1}^{*}(\kappa)$ and $N_{2}^{*}(\kappa)$ vary with $\kappa$.

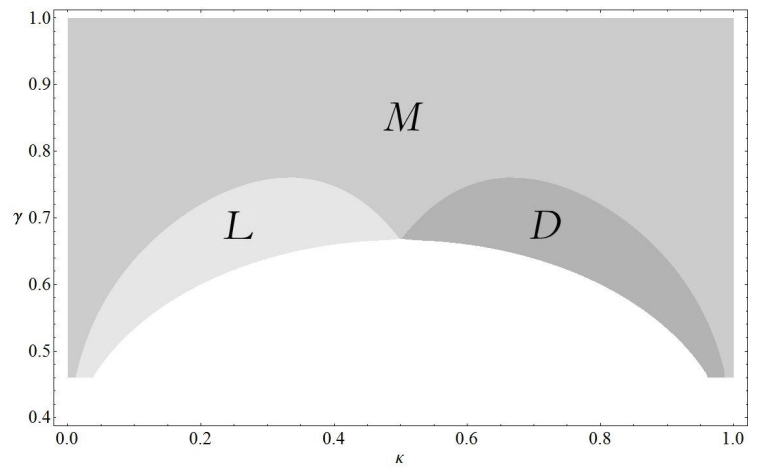

Figure 6: regions in the parameter space $(\kappa, \gamma) \subseteq(0,1) \times(0.4,1)$

The following holds:

- in the (M)edium grey region $N_{1}^{*^{\prime}}(\kappa)>0$ and $N_{2}^{*^{\prime}}(\kappa)<0$.

- in the (L)ight grey region $N_{1}^{*^{\prime}}(\kappa)<0$ and $N_{2}^{*^{\prime}}(\kappa)<0$.

- in the (D)ark grey region $N_{1}^{*^{\prime}}(\kappa)>0$ and $N_{2}^{*^{\prime}}(\kappa)>0$.

Take the values of $\gamma$ corresponding to the points where the inverse $U$ shaped contours of the light and dark areas are maximized with respect to $\kappa$ : take the highest such $\gamma$ and call it $\hat{\hat{\gamma}}$. Clearly, for all $\gamma>\hat{\hat{\gamma}}$ it is true that $N_{1}^{*^{\prime}}(\kappa)>0$ and $N_{2}^{*^{\prime}}(\kappa)<0$. Notice that the maximum attained by the lower contour in Figure 6 - i.e. condition $(\mathrm{A} 7)$ — is $\frac{2}{3}$, hence $\hat{\hat{\gamma}}>\frac{2}{3}$.

Finally, Point 3 follows from showing graphically — graph not reported — that $N_{1}^{*}(\kappa)+N_{2}^{*}(\kappa)<\frac{3 \gamma-1}{1+\gamma} \equiv N^{*}$ for all $(\kappa, \gamma) \subseteq(0,1) \times(0,1)$. Q.E.D.

Proof of Corollary 2 (sketch): point 1 can be proved graphically — graph not reported - by showing that $N_{1}^{*^{\prime}}(\gamma)+N_{2}^{*^{\prime}}(\gamma)>0$ for all the pairs $(\kappa, \gamma)$ such that existence is granted. 
Figure 7 proves point 2. Panel (a) (resp. (b)) shows the parameter region within the constrained region such that $N_{1}^{*^{\prime}}(\gamma)>0\left(\operatorname{resp} . N_{2}^{*^{\prime}}(\gamma)>0\right)$ with the corresponding threshold $\underline{\kappa}(\operatorname{resp} . \bar{\kappa})$.

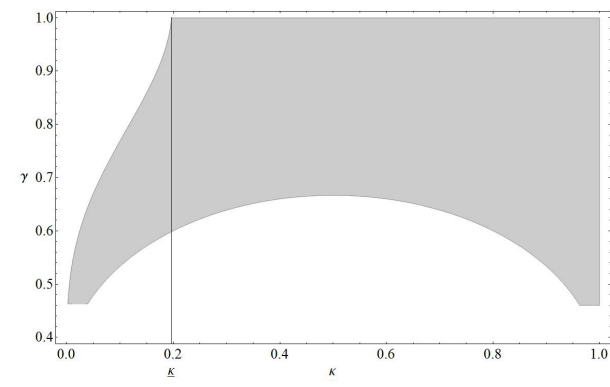

(a) $N_{1}^{*^{\prime}}(\gamma)>0$

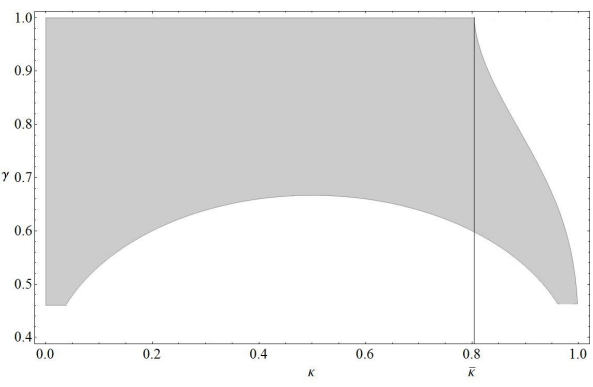

(b) $N_{2}^{*^{\prime}}(\gamma)>0$

Figure 7: regions in the parameter space $(\kappa, \gamma) \subseteq(0,1) \times(0.4,1)$

Q.E.D.

Proof of Proposition 6: first, it is easy to check that condition 4 guarantees result 1. It also guarantees that, if an assembler purchases any number of suppliers and integrates them, single firms supplying the assembler invest 1 (2) if they are of the high (low) specificity type -i.e. they stick with their non integration investment decisions. For the rest, the proof follows the same lines as the proof of previous propositions, with some caveats.

As before, the assembler will buy firms as long as the marginal revenue from buying one more firm is equal to the cost of the next firm to buy. The cost of a firm is unchanged and, in particular, because of conditions 1 and 2, it does not vary within types as the assembler integrates suppliers -other than, of course, for the efficiency loss $\gamma$. The marginal revenue of the assembler, however, varies depending on the types of firms he buys as well as on how much he invests in each new integrated 
division. Notice that, because the production function is linear, the assembler will invest the same in all of its integrated divisions of a given type.

It is not difficult to show that, for $\gamma$ sufficiently close to 1 , the marginal profit from integrating any firm is positive irrespective of how many firms the assembler has already bought, of their type and of how much he invests in them after integration. In particular, comparing the marginal profits, it can be shown that: the assembler first integrates high specificity firms and invests 1 in each integrated division; then he keeps buying high specificity firms but invests 2 in all his high specificity integrated divisions; after having bought all high specificity firms he starts buying low specificity firms and invests 2 in both types of integrated divisions until he has bought all the firms.

Finally, it is straightforward to check that the total profit is higher under full integration with the assembler investing 2 in all the integrated divisions than under non integration. In fact, under integration the total profit is $2 \pi_{2} \gamma-2$, while under non integration it is $\frac{1}{2}\left(\frac{\pi_{1}}{2}-1\right)+\frac{1}{2}\left(2 \pi_{2}-2+\frac{\pi_{1}}{2}\right)=\pi_{2}+\frac{\pi_{1}}{2}-\frac{3}{2}$. The difference is $(2 \gamma-1) \pi_{2}-\frac{\pi_{1}}{2}-\frac{1}{2}$, which is clearly positive under the above conditions. Q.E.D. 
1. L. Colombo, H. Dawid, Strategic Location Choice under Dynamic Oligopolistic Competition and Spillovers, Novembre 2013.

2. M. Bordignon, M. Gamalerio, G. Turati, Decentralization, Vertical Fiscal Imbalance, and Political Selection, Novembre 2013.

3. M. Guerini, Is the Friedman Rule Stabilizing? Some Unpleasant Results in a Heterogeneous Expectations Framework, Novembre 2013.

4. E. Brenna, C. Di Novi, Is caring for elderly parents detrimental to women's mental health? The influence of the European North-South gradient, Novembre 2013.

5. F. Sobbrio, Citizen-Editors' Endogenous Information Acquisition and News Accuracy, Novembre 2013.

6. P. Bingley, L. Cappellari, Correlation of Brothers Earnings and Intergenerational Transmission, Novembre 2013.

7. T. Assenza, W. A. Brock, C. H. Hommes, Animal Spirits, Heterogeneous Expectations and the Emergence of Booms and Busts, Dicembre 2013.

8. D. Parisi, Is There Room for 'Fear' as a Human Passion in the Work by Adam Smith?, Gennaio 2014.

9. E. Brenna, F. Spandonaro, Does federalism induce patients' mobility across regions? Evidence from the Italian experience, Febbraio 2014.

10. A. Monticini, F. Ravazzolo, Forecasting the intraday market price of money, Febbraio 2014.

11. Tiziana Assenza, Jakob Grazzini, Cars Hommes, Domenico Massaro, $P Q$ Strategies in Monopolistic Competition: Some Insights from the Lab, Marzo 2014.

12. R. Davidson, A. Monticini, Heteroskedasticity-and-Autocorrelation-Consistent Bootstrapping, Marzo 2014.

13. C. Lucifora, S. Moriconi, Policy Myopia and Labour Market Institutions, Giugno 2014.

14. N. Pecora, A. Spelta, Shareholding Network in the Euro Area Banking Market, Giugno 2014.

15. G. Mazzolini, The economic consequences of accidents at work, Giugno 2014.

16. M. Ambrosanio, P. Balduzzi, M. Bordignon, Economic crisis and fiscal federalism in Italy, Settembre 2014.

17. P. Bingley, L. Cappellari, K. Tatsiramos, Family, Community and Long-Term Earnings Inequality, Ottobre 2014.

18. S. Frazzoni, M. L. Mancusi, Z. Rotondi, M. Sobrero, A. Vezzulli, Innovation and export in SMEs: the role of relationship banking, Novembre 2014.

19. H. Gnutzmann, Price Discrimination in Asymmetric Industries: Implications for Competition and Welfare, Novembre 2014.

20. A. Baglioni, A. Boitani, M. Bordignon, Labor mobility and fiscal policy in a currency union, Novembre 2014.

21. C. Nielsen, Rational Overconfidence and Social Security, Dicembre 2014.

22. M. Kurz, M. Motolese, G. Piccillo, H. Wu, Monetary Policy with Diverse Private Expectations, Febbraio 2015.

23. S. Piccolo, P. Tedeschi, G. Ursino, How Limiting Deceptive Practices Harms Consumers, Maggio 2015.

24. A.K.S. Chand, S. Currarini, G. Ursino, Cheap Talk with Correlated Signals, Maggio 2015. 
25. S. Piccolo, P. Tedeschi, G. Ursino, Deceptive Advertising with Rational Buyers, Giugno 2015.

26. S. Piccolo, E. Tarantino, G. Ursino, The Value of Transparency in Multidivisional Firms, Giugno 2015.

27. G. Ursino, Supply Chain Control: a Theory of Vertical Integration, Giugno 2015. 